Article (refereed) - postprint

Edeline, Eric; Groth, Andreas; Cazelles, Bernard; Claessen, David; Winfield, lan J.; Ohlberger, Jan; Vollestad, L. Asbjorn; Stenseth, Nils C.; Ghil, Michael. 2016. Pathogens trigger top-down climate forcing on ecosystem dynamics. Oecologia, 181 (2). 519-532. 10.1007/s00442-016-3575-8

(C) Springer-Verlag Berlin Heidelberg 2016

This version available http://nora.nerc.ac.uk/507191/

NERC has developed NORA to enable users to access research outputs wholly or partially funded by NERC. Copyright and other rights for material on this site are retained by the rights owners. Users should read the terms and conditions of use of this material at

http://nora.nerc.ac.uk/policies.html\#access

This document is the author's final manuscript version of the journal article, incorporating any revisions agreed during the peer review process. There may be differences between this and the publisher's version. You are advised to consult the publisher's version if you wish to cite from this article.

The final publication is available at Springer via http://dx.doi.org/10.1007/s00442-016-3575-8

Contact CEH NORA team at noraceh@ceh.ac.uk

The NERC and CEH trademarks and logos ('the Trademarks') are registered trademarks of NERC in the UK and other countries, and may not be used without the prior written consent of the Trademark owner. 


\title{
Pathogens trigger top-down climate forcing on ecosystem dynamics
}

\author{
Running headline: Multiple stressors and food-web apexes
}

Eric Edeline*a, Andreas Groth ${ }^{\mathrm{b}, \mathrm{c}}$, Bernard Cazelles ${ }^{\mathrm{d}, \mathrm{e}}$, David Claessen ${ }^{\mathrm{b}, \mathrm{e}}$, Ian J. Winfield ${ }^{\mathrm{f}}$, 5 Jan Ohlberger ${ }^{\mathrm{g}}$, L. Asbjørn Vøllestad ${ }^{\mathrm{g}}$, Nils Chr Stenseth ${ }^{\mathrm{g}}$, Michael Ghil ${ }^{\mathrm{b}, \mathrm{c}, \mathrm{h}}$

*Corresponding author: eric.edeline@,upmc.fr

a: Sorbonne Universités / UPMC Univ. Paris 06/ CNRS/ INRA/ IRD/ Paris Diderot Univ. Paris 07/ UPEC/ Institut d'Ecologie et des Sciences de l'Environnement - Paris (iEES-Paris), 7 quai St Bernard, F-75252 Paris, France.

b: Environmental Research and Teaching Institute (CERES-ERTI), Ecole Normale Supérieure, 24 Rue Lhomond, 75230 Paris cedex 05, France.

c: UCLA, Dept. of Atmospheric and Oceanic Sciences and Institute of Geophysics and Planetary Physics, University of California, Los Angeles, CA 90095-1565, USA.

d: IRD-UPMC, UMI 209 UMMISCO, 93143 Bondy, France

e: Eco-Evolutionary Mathematics, UMR 8197, Ecole Normale Superieure, 46 rue d'Ulm 75230 Paris cedex 05, France.

f: Lake Ecosystems Group, Centre for Ecology \& Hydrology, Lancaster Environment Centre, Library Avenue, Bailrigg, Lancaster, LA1 4AP, UK.

g: Center for Ecological and Evolutionary Synthesis (CEES), Department of Biosciences, University of Oslo, P.O. Box 1066 Blindern, 0316, Oslo, Norway.

h: Dept. of Geosciences and Laboratoire de Météorologie Dynamique (CNRS and IPSL), 24 Rue Lhomond, 75230 Paris cedex 05, France.

30 Author Contributions: EE led manuscript writing, IJW provided the data, $\mathrm{AG}$ and $\mathrm{BC}$ ran the analyses and produced associated figures, and all authors contributed to results interpretation and manuscript improvement. 
Multiple stressors and food-web apexes

\section{Abstract}

Evaluating the effects of climate variation on ecosystems is of paramount importance for our ability to

35 forecast and mitigate the consequences of global change. However, the ways in which complex food webs respond to climate variations remain poorly understood. Here, we use long-term time series to investigate the effects of temperature variation on the intraguild-predation (IGP) system of Windermere (UK), a lake where pike (Esox lucius, top predator) feed on small-sized perch (Perca fluviatilis) but compete with large-sized perch for the same food sources. Spectral analyses of time series reveal that

40 pike recruitment dynamics are temperature-controlled. In 1976, expansion of a perch pathogen into the lake severely impacted large perch and favoured pike as the IGP-dominant species. This pathogeninduced regime shift to a pike-dominated IGP apparently triggered a temperature-controlled trophic cascade passing through pike down to dissolved nutrients. In simple food chains, warming is predicted to strengthen top-down control by accelerating metabolic rates in ectothermic consumers, while

45 pathogens of top consumers are predicted to dampen this top-down control. In contrast, the local IGP structure in Windermere made warming and pathogens synergistic in their top-down effects on ecosystem functioning. More generally, our results point to top predators as major mediators of community response to global change, and show that size-selective agents (e.g., pathogens, fishers or hunters) may change the topological architecture of food-webs and alter whole-ecosystem sensitivity to

50 climate variation.

Key words: Body size, Parasites, Population structure, Singular spectrum analysis, Wavelet analysis. 
Multiple stressors and food-web apexes

\section{Introduction}

The anthropogenic increase in global temperatures since the late $19^{\text {th }}$ century is now well documented,

55 and its projected continuation is highly likely (IPCC 2014). In parallel, it has been suggested that pathogen outbreaks in terrestrial and marine ecosystems have increased in number and severity (Harvell 2002). On land, warming often favours the transmission of vector-borne disease by stimulating the reproduction, development and range expansion of arthropod vectors, while in seas warming-induced coral bleaching seems to involve thermophilic pathogens in combination with other

60 causal agents (Harvell 2002). Warming may also alter host social behaviour and contact rates, encounters with infective stages in the environment, host births and deaths rates, and host immune defences (Altizer et al. 2006). However, to date there have been few in-depth investigations of how climate and pathogens interactively affect whole ecosystem dynamics (but see Wilmers et al. 2006).

65 Taken separately, the ecological effects of global warming and pathogens on food chains are attracting increasing research efforts. Alone, higher temperatures often reinforce top-down control in food chains dominated by ectothermic top predators, by increasing consumption rates of ectothermic consumers faster than primary production. Various models on the thermal dependency of metabolic rates predict this general effect (Vasseur and McCann 2005; Ohlberger et al. 2011a); This effect has also been

70 consistently observed in multiple experimental and natural systems (O'Connor et al. 2009; Rall et al. 2009; Yvon-Durocher et al. 2010; Vucic-Pestic et al. 2011; Shurin et al. 2012; Edeline et al. 2013). In parallel, pathogens and parasites may have severe impacts on host populations, with potentially indirect effects cascading down along food chains (Oksanen et al. 1981; Wilmers et al. 2006; Hudson et al. 2006; Holdo et al. 2009). In particular, by reducing the densities of their host, parasites of top

75 consumers trigger a release from top-down control in food chains (Wilmers et al. 2006), and thus 
Multiple stressors and food-web apexes

oppose the effects of the thermal activation of metabolic rates.

Simple linear food chains, however, are rarely found in nature and the effects of pathogen invasions may be less intuitive in more complex food webs. For instance, intraguild predation (IGP) is a 80 widespread form of interaction that involves competition between a prey and its predator for common food resources (Holt and Polis 1997). In an IGP system, pathogens can increase vulnerability of infected individuals to cannibalism or predation, resulting in a reversed species dominance in the IGP hierarchy (Hatcher et al. 2006). Such reorganizations may potentially alter predictions from food-chain theory concerning how communities will respond to invading pathogens. Therefore, studies of climate-

85 pathogen interactions on ecosystem dynamics should not ignore IGP. In this paper, we use long-term data from the Windermere ecosystem in order to understand how the outbreak of a pathogen in an IGP system influenced the direction and strength of climate forcing on community dynamics.

Windermere is a glacial valley lake in northwest England (UK), divided by shallows into a mesotrophic

90 north basin and a south basin that is eutrophic due to sewage input. The two main predatory fish species are pike (Esox lucius, IG predator) and perch (Perca fluviatilis, IG prey). Both species interact through IGP, in which pike prey on small-sized perch but compete with large-sized perch for the same food sources (Edeline et al. 2008; Langangen et al. 2011; Winfield et al. 2012). This food-web structure changed in 1976 when an outbreak of a perch-specific pathogen extirpated over $98 \%$ of the adult perch

95 population, particularly fast-growing and large-sized individuals (Bucke et al. 1979; Edeline et al. 2008; Ohlberger et al. 2011b; Ohlberger et al. 2011c). For reasons that are not fully understood, perch was the only fish species affected by the disease in Windermere. The primary pathogenic agent remained unidentified, but was possibly a columnaris bacterium that spread in roach (Rutilus rutilus), 
Multiple stressors and food-web apexes

which at that time was very rare in Windermere, and perch populations through United Kingdom

100 during the early 1960s (Ajmal and Hobbs 1967). The disease was characterized by perforating skin lesions and fish died from multiple bacterial and fungal infections (Bucke et al. 1979).

In Windermere, truncation of the perch age and size distribution started in the early 1960s (Fig. S1), i.e., synchronous with the spread of the disease through the United Kingdom, but the massive perch kill

105 occurred only in 1976. Since then, the age and size structure of perch has remained truncated and adult perch have remained rare (Fig. S1). Interestingly, total perch biomass remained almost constant because biomass loss in adults was compensated by a corresponding increase in the biomass of juvenile perch. This so-called "stage-specific biomass overcompensation" was mediated by an increased adult fecundity due to relaxed resource competition, and by an increased juvenile survival due to relaxed

110 cannibalism from adults (Ohlberger et al. 2011d). In parallel the mean number (Fig. 1), body size and, to a lesser extent, age of pike (Fig. S1) have increased, presumably due to higher food availability linked to decreased competition from large perch and increased production of small perch. Note that the slight increase in the mean age of pike, indicating increased survival rate, was also potentially related to a reduced fishing effort by the scientific gillnet fishery (Langangen et al. 2011).

115

This positive response of pike to the pathogen outbreak was particularly expected in Windermere because the IGP system is a life-history IGP system, in which the predator competes with the adult stage to feed on the juvenile stage of the prey (Abrams 2011). Hence, pike benefited both from the reduction of competition linked to depletion of adult perch, and from the stage-specific biomass 120 overcompensation that increased production of juvenile perch. Theoretical models further predict that predators specialized on either adults (e.g., pathogen of adult perch) or juveniles (e.g., pike on juvenile 
perch) could, under certain conditions, facilitate (favour) each-other through stage-specific biomass overcompensation in the prey (De Roos et al. 2008). Accordingly, in Windermere there is some evidence that predation from pike might have favoured the pathogen outbreak. Signs of the disease on

125 perch were reported as early as 1963 (Bucke et al. 1979) and perch age and size truncation indeed started during the 1960s (Fig. S1), but the spread of the pathogen and massive perch kill occurred only in 1976 and coincided with a peak in predation pressure from pike in both basins (as estimated from the perch/pike abundance ratio, Edeline et al. 2008). In turn, the pathogen outbreak clearly favoured pike (Figs. 1 and S1).

We hypothesized that the pathogen-induced increase in numbers and body size of pike in the Windermere IGP should have strengthened top-down control in the food web (i.e., increased pike control over food-web dynamics), and thus should have acted synergistically with the thermal activation of top-predator consumption rates. This is in contrast with a simple food chain in which

135 pathogens of top-predators are expected to relax top-down control and thus oppose the physiological effects of warming. Our results support this prediction and thus show that the food-web architecture (here IGP vs. food chain) is pivotal in determining the effects of multiple stressors on ecosystems.

\section{Materials and Methods}

The data

In this study we handled in parallel 12 time series for which we provide an interaction graphic in Fig. 2. The data set was collected between 1946 and 2002 from each of the north or south basin of Windermere, and includes observations of perch (small and large), pike (small and large), water 
Multiple stressors and food-web apexes

145 temperature (measured at just one site, see below), and the key nutrient phosphorus.

Scientific monitoring in Windermere started in 1943 and 1944 for perch and pike, respectively, and continues with effectively no change in gear type and fishing methods. Perch are sampled using traps set on spawning grounds from mid-April to early June. Hence, only mature (age 2 or older) perch are

150 captured. Pike are sampled in winter (usually from mid-October to late December) using $64 \mathrm{~mm}$ gill nets, which target pike from age 3 years. Captured fish are measured for length and weight, and the left opercular bone is removed to determine the age of the fish to the nearest year. For logistical reasons, opercular bones were aged up to 2002 .

155 Yearly catch per unit effort (CPUE) is defined for perch as the number of fish per number of traps deployed for 6 weeks on the spawning ground; for pike it is the number of fish per net per day. We separated CPUEs between recruits (hereafter "small") and older individuals (hereafter "large") in both perch and pike, defining recruits as age- 2 perch and age-3 pike, and older individuals as age 3-6 perch and age 4-9 pike. In this way, we were able to discriminate processes affecting the first years of fish

160 life from processes related to later development stages. This distinction is important because mortality is highest and most variable during early stages in fish, and recruitment is thus the most informative stage to decipher the mechanisms driving fish population dynamics.

We further separated CPUEs for the north and south basins of the lake because pike disperse from the 165 former resource-poor basin (source habitat) to the latter resource-rich basin (sink habitat) where survival is lower (Haugen et al. 2007). These north-to-south movements of pike are highly dependent on the basin-to-basin gradient in perch abundances (Haugen et al. 2006). Separating into north and 
Multiple stressors and food-web apexes

south CPUEs also accounts for the fact that basin-to-basin perch dispersal is limited (Bodaly et al. 1989).

170

Together with these biological data, surface water temperatures were recorded on a near-daily basis at the junction between the north and south basins of the lake. Hence, while all other time series were recorded at the basin level, temperature data was recorded at the lake level (Fig. 2). Here, we have used the seasonal number of degree-days above $14^{\circ} \mathrm{C}$ - a pertinent metric for biological rates in Windermere

175 (Haugen et al. 2007) - summing among the spring (May-June) and late summer (August-September) temperatures. Because temperature was sometimes not measured on a given day, we have bootstrapped the data to make sure that no sampling effects were present in our temperature metrics. We randomly sampled (with replacement) 3,000 daily temperatures in a given month, summed number of degree days above $14^{\circ} \mathrm{C}$ and divided this sum by 100 to obtain the sum for 30 days. This resampling altered

180 our temperature metrics very marginally, indicating that the initial bias was minor. The obtained two sets of temperature (spring vs. summer) were only weakly correlated, with Pearson's $\mathrm{R}^{2}=0.15$.

We found in the M-SSA analyses that an NAO index contributed less variance to the ecological time series than the local temperature data, and that it did not provide further information when included

185 together with the local temperature. We therefore did not include any NAO index in our analyses, as the contribution of such indices is - on the one hand - already reflected in the temperatures and, on the other, may be somewhat ambiguous, cf. Pokorná and Huth (2015). Finally, we incorporated data on mean concentrations of soluble reactive phosphorus during the first 4 weeks of the year (hereafter simply phosphorus) in each basin, for which measurements started in 1946 in both basins (hence our 190 time series spanned the 1946 to 2002 period). 


\section{Time series analysis}

Traditionally, time series analysis in ecology has relied on time-domain, parametric methods of the auto-regressive type. Such methods, however, assume the ecological processes that generate the time

195 series to be both linear and stationary, i.e., they assume that the characterisitcs of the time series do not change in time. Instead, the complex interactions present in the data at hand led us to consider two complementary methods that are non-parametric, data adaptive and that have been successfully applied for linear and nonlinear processes that involve both stationary and non-stationary dynamics.

200 We first applied multichannel singular spectrum analysis (M-SSA) to identify overall spatio-temporal behaviour of all time series processed simultaneously, and to reduce the complexity of the 12 time series to a few oscillatory components. Then, because M-SSA assumes at least weak temporal stationarity, we addressed the non-stationarity issue by a subsequent wavelet analysis that can find localized intermittent periodicities (Cazelles et al. 2007) but which, on the other hand, can process

205 simultaneously only up to two time series (but see Rouyer et al. 2008).

\section{Multichannel singular-spectrum analysis (M-SSA)}

The decomposition of a general function of time into separate oscillatory components traditionally relies on the Fourier transform, which approximates the original function by fitting a linear

210 combination of sine and cosine functions, whose periods are integer multiples of a basic period. The key idea of SSA, or M-SSA for multiple time series, is to decompose the time series into trends, oscillatory components and noise. SSA and M-SSA, however, replace the sines and cosines of Fouriertype methods by the eigenvectors of the lag-covariance matrix $C$ of the time series (see below), and 
Multiple stressors and food-web apexes

the a priori prescribed set of periods of the Fourier methods by the eigenvalue spectrum of this matrix.

215 Eigenvectors produced by diagonalizing $C$ are called spatio-temporal empirical orthogonal functions (ST-EOFs), and the corresponding eigenvalues provide the variance captured by each STEOF. The diagonalization is achieved by singular value decomposition, hence the name "singular spectrum analysis," and the eigenvalue spectrum of the present analyses is shown in Fig. S2.

220 The lag-covariance matrix $C$ of the time series is the matrix of covariances between time series values at $t$ and at $t+k$, with $k$ varying from 0 to $M-1$, and the eigenvalues and eigenvectors are obtained by diagonalizing $C$. The maximum lag $M$ used in the analysis optimizes the trade-off between spectral resolution and temporal resolution. Spectral resolution is given by the range of frequencies that can be detected and it increases when $M$ increases while temporal

225 resolution corresponds to the number of "windows" sampled from the time series and it decreases when

$M$ increases. In particular, increasing temporal resolution increases the power of the method to detect changes in the amplitude of oscillations from one sampled window to the next. The optimal trade-off here was achieved for $M=16$ years. By optimizing $M$, the method can detect changes in the amplitude of the oscillations and the stationarity assumption is thus slightly relaxed.

If one assumes that it is a mixture of mechanisms generating different cyclicities that produce ecological time series, ST-EOF extraction can be understood as a procedure that deciphers these different mechanisms. Projecting the time series onto the ST-EOFs yields the corresponding principal components, whose linear combinations, in turn, yield partial reconstructions of the time series that are 235 associated with a particular oscillatory component; the latter are referred to as reconstructed components or RCs (Ghil and Vautard 1991; Ghil et al. 2002). 
Typically, an oscillatory mode is characterized by a pair of nearly equal eigenvalues and associated principal components that are in approximate phase quadrature (Vautard and Ghil 1989; Plaut and

240 Vautard 1994; Ghil et al. 2002), i.e., one ST-EOF in the pair can be gotten from the other by a shift of one-quarter period. Hence, an RC pair predicts how the time series would look like if it were produced only by the corresponding mechanism, as identified from its resultant cyclicity. For a more reliable separation of ST-EOF pairs, we used here the recently developed variance-maximisation (varimax) rotation of the ST-EOFs. This approach reduces mixture effects between distinct oscillatory 245 components and improves the biological interpretability of the results (Groth and Ghil 2011).

An ST-EOF pair is the counterpart in SSA analysis of a sine-and-cosine pair with the same frequency in Fourier analysis. However, to avoid any misinterpretation of random fluctuations as oscillations, we performed a Monte Carlo statistical test and compared the variance captured by each pair of ST-EOFs

250 with that in a large ensemble of random-walk noise surrogates (Allen and Robertson 1996; Allen and Smith 1996; Groth and Ghil 2015). In this analysis, we considered 21 ST-EOF pairs. Provided that the variance of a pair of ST-EOFs substantially exceeds the hypothetical level of such a random-walk noise process - taken as the null-hypothesis model - the corresponding RCs represent significant oscillatory behaviour.

We performed our M-SSA analyses by using the freely available SSA-MTM toolkit (http://research.atmos.ucla.edu/tcd//ssa/). Further information and technical details on the method and software can be found as Electronic Supplemental Material, as well as in the review paper of Ghil et al (2002), in the User's Guide of the SSA-MTM Toolkit (at http://www.atmos.ucla.edu/tcd/ssa/guide/), 
Multiple stressors and food-web apexes

260 and in the beginner's guide to SSA (http://environnement.ens.fr/IMG/file/DavidPDF/SSA beginners guide_v9.pdf). Further technical details on the method and computational steps may be found in the Electronic Supplementary Material.

\section{Wavelet analysis}

265 Fourier transform and associated sine and cosine functions can not accommodate temporal or shape discontinuities which are common in ecological time time series. ST-EOFs in SSA are more data adaptive than Fourier transform, but still assume some stationarity in the oscillatory behaviour of the time series. In contrast, wavelet transform uses more flexible functions named "mother wavelet" (here we used a Morlet wavelet, Cazelles et al. 2007) that can account for both temporal (via translations)

270 and shape (via dilations) discontinuities in the original time series, and are thus particularly well adapted to exploring the changing behaviour of ecological time series (Cazelles et al. 2008).

Specifically, after convolving each time series with the scaled and translated version of a Morlet wavelet, we computed the wavelet power spectrum (WPS), which quantifies the variance of the time

275 series both in frequency and time. The WPS is also used to compute the global wavelet power spectrum (GWPS) by temporally integrating the WPS values over all local spectra. The latter provides an estimation of the global frequency spectrum, like in M-SSA.

To explore the joint oscillatory behaviour of two time series we computed the wavelet coherence that

280 provided (i) tests for phase locking (i.e., simultaneous oscillation on the same frequency) of time series pairs, and (ii) phase difference between the two time series of a pair, from which we computed the instantaneous time lag between the two time series. As for the M-SSA significance test, the variance 
Multiple stressors and food-web apexes

described by the WPS was compared to that of a data-driven random-walk noise null hypothesis. Significance levels were derived from bootstrapped time series with the parameter of the stochastic process determined from the time series at hand (Cazelles et al. 2014).

We performed the wavelet analyses using well-established algorithms for wavelet power spectrum, wavelet coherency and phase computation, implemented in Matlab 2015a. The specific functions used herein can be downloaded from https://dl.dropboxusercontent.com/u/192975/Wavelets_EETS.zip. Note that these functions work on any Matlab release since Matlab2001a. More details on the method are provided as Electronic Supplemental Material.

\section{Results}

The M-SSA and wavelet analysis were in agreement in identifying a medium-period, 7-8 year

295 oscillation involving summer temperature, pike CPUE, small perch CPUE and phosphorus (Figs 1, 3 and 4). Additionally, both methods identified a long-period, 13-15-year oscillation of large perch (Fig. 7), that wavelets further suggested to be also present in pike and phosphorus towards the end of the time series (Figs 3 and 4). Finally, M-SSA identified a short-period, 2-3-year oscillation involving spring temperature, phosphorus, as well as small perch and small pike in the south basin (Fig. 8).

\section{Medium-period oscillations}

The M-SSA shows that the 7-8-year oscillation was overall present in summer temperature, pike in both basins, as well as in small perch and phosphorus in the south basin of the lake (Fig. 1). Examination of GWPSs, that provide an integrated wavelet spectrum over the whole time series, 305 confirms that this 7-8-year oscillation was strongest in pike (GWPS in Figs. 3C, D, G, H) and 
Multiple stressors and food-web apexes

phosphorus in the south basin (GWPS in Fig. 4B), but was also significant in large perch in the south basin (GWPS in Fig. 3F). Additionally, WPSs further show that the 7-8-year oscillation was also transiently present in large perch in the north basin (from 1960 to 1970, WPS in Fig. 3B), a well as in small perch in both the north (1955-1965, WPS in Fig. 3A) and south (1985-2000, WPS in Fig. 3E) 310 basins.

In order to examine more specifically the link between pike and perch in this 7-8-year frequency range, we ran a wavelet coherence analysis which provided a co-spectrum for both species (Fig. 5). We did not include here the intraspecific co-spectrums (i.e., small vs. large fish of the same species), which

315 show strong phase locking (i.e., joint oscillations) essentially reflecting cohort dynamics (see Fig. S3). Coherence analysis confirmed phase locking of pike and perch in the 7-8-year frequency range. In the north basin, phase locking was transient and most significant between large pike and small perch from 1980 (Fig. 5B), between small pike and large perch during the 1980s (Fig. 5C), and between large pike and large perch during the 1960s and 1980s (Fig. 5D). In the south basin of the lake, the 7-8-year joint

320 oscillations of pike and perch were very clear and neat for small pike and large perch from 1970 onwards (Fig. $5 \mathrm{G}$ ), but were also transiently present in large pike and large perch for the same time period (Fig. 5H).

The non-stationary nature of the 7-8-year oscillation was evident in both the WPSs and coherence

325 analyses (Figs. 3, 4 and 5), which both revealed a regime shift in the 1970s when the 7-8-year oscillations synchronously emerged in temperature, pike, and phosphorus. The 7-8-year oscillations started in 1970 in small pike in both basins (WPSs in Figs. 3C, G) as well as in phosphorus in the south basin (WPS in Fig. 4B), and slightly later in large pike (WPSs in Figs. 3D, H). 1970 also marks the 
Multiple stressors and food-web apexes

onset of a strong link between small pike and large perch in the south basin (coherence in Fig. 5G, see

330 above). This regime shift was also apparent in M-SSA where the amplitude of the RCs increased over time for all of the time series (Fig. 1).

In contrast, the 7-8-year oscillation of summer temperature showed no abrupt change but instead increased gradually from the early 1960s (orange colour in WPS in Fig. 4D) and became statistically

335 significant only during the late 1970s. Interestingly, this increasing amplitude of oscillations in summer temperatures paralleled a steady increase in their mean value (Fig. 1).

A key question for the observed temperature-pike-perch-phosphorus oscillations was whether they reflected a bottom-up or a top-down causal effect of temperature. To answer this question we explored

340 causality among oscillating variables in the 7-8-year frequency range using lags among the reconstructed components in both the M-SSA and wavelet coherence analysis, assuming that the cause preceded the effect. Lags among the M-SSA reconstructed components (Fig. 1) show that, on average, thermal forcing was leading, followed by small perch in the south basin (0.2-year delay), phosphorus in the south basin (1.6-year delay), small pike in both basins (2.5-year delay), and large pike in both 345 basins (3.7-year delay, i.e., large pike and summer temperature were in phase opposition, see Fig. 1).

In contrast with the M-SSA, lags among the reconstructed components in the wavelet coherence analysis assumed no stationarity, and were thus more adapted to study abrupt changes in the perch-pike link. In the north basin, pike and perch tended to oscillate in perfect phase opposition across the whole 350 time period, with a slightly varying lag (Fig. 6A). In the south basin of the lake, where the pike-perch link was most significant (see above), pike and perch oscillated in perfect synchrony up to 1970, after 
which small pike started to lag behind perch by about 3 years (Fig. 6B).

\section{Long-period oscillations}

355 Both the M-SSA and the wavelet analysis show that perch oscillated on a 13-15-year periodicity. This signal was found to be significant by the M-SSA in large perch only, for which the signal was very strong (Fig. 7). Wavelets further reveal that this 13-15-year oscillation shifted from large perch (WPSs in Figs. 3B, F) to pike around the mid 1970s (WPSs in Figs. 3C, D, G, H), thus confirming the regime shift observed in the 7-8-year frequency range. In both basins, the shift of the 13-15-year oscillation

360 from perch to pike was first transmitted to the small, and then to the large pike (WPSs in Figs. 3C, D, $\mathrm{G}, \mathrm{H}$ ), indicating processes operating during pike recruitment. Interestingly, wavelets also suggest that phosphorus also started to oscillate on a 13-15-year periodicity at the same time as pike in the south basin of the lake (from 1980, WPS in Fig. 3H for pike and WPS in Fig. 4B for phosphorus).

\section{Short-period oscillations}

The M-SSA shows that the fast, 2-3-year oscillation was present in spring temperature, phosphorus in the north (but not south) basin, and in small pike and small perch in the south basin (Fig. 8). GWPS confirmed this significant oscillation only for spring temperature (Fig. 4C). Hence, M-SSA and wavelet analysis tended to diverge on the significance of this fast oscillation.

Time-lag analysis in the M-SSA (Fig. 8) shows that, on average, spring temperature and phosphorus in the north basin were negatively correlated with no lag, because a 1.2-year delay indicates an exact phase opposition in this quasi-biennial cycle. Time lag was 0.6 - and 0.1 -year in perch and pike, respectively (Fig. 8). 
Multiple stressors and food-web apexes

375

\section{Discussion}

Ecosystems are generally subjected to multiple perturbations acting simultaneously. To date, our knowledge of how complex ecosystems will respond to such multiple stressors remains poor. The Windermere data provide a rare opportunity to examine the interactive effects of pathogens and climate

380 variation on a lake food web, in which top consumers (perch and pike) interact through intraguild predation (IGP). We coupled two complementary spectral analyses (M-SSA and wavelet analysis) that allowed us to deal with the complexity and non-stationarity of the 12 time series in parallel. Our results show that pathogen-induced dominance of the IGP predator (pike) has magnified the sensitivity of the whole ecosystem to top-down thermal forcing.

385

\section{7-8-year oscillations: pathogen-triggered top-down forcing}

Both M-SSA and wavelets were in agreement in identifying a 7-8-year oscillation in summer temperature, pike, perch and phosphorus. Such a 7-8-year oscillation of temperatures in England has previously been reported (Plaut et al. 1995), and probably reflects corresponding oscillations in sea

390 level pressures and sea surface temperatures over the North Atlantic basin (Feliks et al. 2004; Feliks et al. 2010; Feliks et al. 2013). Examination of the chain of causalities through time lags suggests that these thermal oscillations intially propagated into the Windermere ecosystem through a modulation of juvenile survival in perch and pike.

395 Time lags in the M-SSA clearly show that a warm summer was followed by increased numbers of small (age-2) perch with almost no lag, and by increased numbers of small (age-3) pike 2.5 years later (Fig. 1). This result confirms previous studies showing a positive effect of warm summer temperature on 
Multiple stressors and food-web apexes

perch and pike recruitment in Windermere (Paxton et al. 2004; Paxton et al. 2009), and further suggests that warm summers increase (i) survival at age $1+$ and $2+$ in perch and (ii) survival at age $0+$ and/or

400 fecundity in pike. Wavelet coherence in the 7-8-year frequency range further suggests that this positive effect of warm temperature on small pike numbers was, at least partly, mediated by the increased numbers of $2+$ perch. Specifically, small (age-3) pike started lagging about 3 years behind small (age2) perch around 1975 (Fig. 7B). This 3-year lag suggests that age-2 perch became an important food source for pike after the pathogen outbreak, such that increased abundances of age- 2 perch in year $t$ translated into increased numbers of age-3 pike in year $t+3$.

Time lags in both M-SSA and wavelets further suggest that, after an initial modulation of perch and pike recruitment, thermal oscillations propagated down to the phosphorus level through a pikemediated trophic cascade in the south basin. Several observations support this interpretation.

First, phosphorus peaked on average 1.6 year after a warm summer (Fig. 1), a lag that seems too long to be consistent with any abiotic, meteorological mechanism (e.g., wind-driven lake mixing, or rainfall and runoff). Wind and/or rainfall in summer may possibly affect phosphorus the following January $(+0.5 \mathrm{y}$ lag), or wind and/or rainfall in winter could be in some way correlated to temperature the

415 following summer (-0.5y lag). Instead, the observed +1.6 -year lag is consistent with a trophic cascade, in which a positive effect of summer temperature on pike in year $t$ through elevated survival of $0+$ pike and/or adult fecundity resulted in increased predation on zooplanktivorous fish in year $t+1$, increased zooplankton bundances, decreased algal concentrations and phosphorus uptake by algae, and ultimately increased phosphorus concentrations in January at time $t+2$ or about 1.5 year after a warm summer. 
Multiple stressors and food-web apexes

Second, wavelets confirm that phosphorus oscillations were tightly linked to pike oscillations in the south basin, and thus strongly suggested a pike control on phosphorus concentration in Windermere. Specifically, the onset of the 7-8-year oscillation of phosphorus in the 1970s (Fig. 4 B) was synchronized with the onset of the 7-8-year oscillation in pike in both basins (Figs. 3 C, D, G, H). This

425 high synchrony demonstrates a rapid top-down effect of pike on phosphorus, because a bottom-up effect of phosphorus on pike recruitment would have implied a lag in the onset of pike oscillations.

Interestingly, our results show that pike were much more efficient than large perch in driving a trophic cascade in Windermere, probably because they are more piscivorous than perch. In particular, in winter 430 pike feed extensively on Arctic charr (Salvelinus alpinus) and on the recently introduced roach (Rutilus rutilus) (Winfield et al. 2012), two fish species that are highly efficient predators of large pelagic zooplankton (e.g., Daphnia sp.) which, in turn, are strong algal grazers.

Finally, this temperature-driven trophic cascade in Windermere showed an interesting spatial structure.

435 Pike oscillations emerged mainly in the north basin (higher variance explained by the 7-8-year oscillation, see Fig. 1), and cascaded down to the phosphorus level in the south basin. This propagation fits with studies on pike population dynamics in Windermere showing that pike disperse from the resource-poor north basin (source habitat) to the resource-rich south basin (sink habitat) where survival is lower (Haugen et al. 2006; Haugen et al. 2007). In contrast, in the north basin phosphorus 440 oscillations were mainly climate, bottom-up driven (see below).

An important aspect of the temperature-driven, pike-mediated trophic cascade in Windermere is its pathogen-induced facilitation. Specifically, pike benefited both from the reduction of competition 
Multiple stressors and food-web apexes

linked to depletion of adult perch by the pathogen, and from the stage-specific biomass

445 overcompensation that increased production of juvenile perch (see the introduction). The resultant increase in pike numbers (Fig. 1), age and size (Fig. S1), reinforced the top-down control of the whole food web by pike, and thus facilitated the thermal control of ecosystem dynamics acting through pike recruitment. In parallel, a constant increase in mean summer temperatures (see temperature trend in Fig. 1) probably also favoured an increased top-down control of the food chain through the activation

450 of pike metabolism (see introduction), and thus ultimately paved the way towards a mutual facilitation between pike and the pathogen that triggered the regime shift. Hence, our results support the emergent view that ecosystem regime shifts are often favoured by gradual climate change, but triggered by acute stressors such as fisheries or, here, pathogens (Möllmann and Diekmann 2012).

\section{3-15-year oscillation: cohort resonance in perch and pike}

Beside the medium-period oscillations we detected low-frequency oscillations with an approximate 1315-year period in the fish populations (Figs. 1, 3) which shifted from large perch to pike around the years of pathogen outbreak (Figs. 3D-D, F-H). A 13-15-year period corresponds to approximately five perch generations and three pike generations. We here estimated the generation time of 2.7 years in

460 perch and 5.1 years in pike from the mean age of mature females weighted by their fecundity (the perch data were available for 1944-1964, and the pike data for 1963-2003; Note also that age at maturity in perch decreased after the pathogen outbreak (Ohlberger et al. 2011c)).

A common oscillatory period of pike and perch dynamics despite different generation times precludes 465 delayed density dependence as a possible underlying mechanism for these 13-15-year oscillations (Gurney and Nisbet 1985). Instead, these slow oscillations likely reflected a "cohort resonant" effect, 
defined as a low-frequency variability produced by a combination of age-structured interactions and stochastic (climate-driven) recruitment (Bjørnstad et al. 2004; Hidalgo et al. 2011). In Windemere, cohort resonance of perch and pike is suggested by the 13-15-year periodicity which arguably 470 represents a sub-harmonic of the 7-8-year oscillation of summer temperatures.

Further support for the "cohort resonance" hypothesis comes from the fact that 13-15-year oscillations emerged in fish populations only when old and large perch or pike individuals were present (as controlled by the pathogen). Accordingly, slow oscillations shifted from large perch to pike around the

475 mid-1970s, as the pathogen was reorganizing the age and size structure of the perch and pike populations (Fig. S1). Interestingly, the pathogen truncated perch age and size structure more severely in the north than in the south basin (Fig. S1), and the cohort resonant effect shifted from perch to pike faster in the north basin (10 years transition, WPSs in Figs. 3B-D) than in the south basin (20 years transition, , WPSs in Figs. 3F-H). Hence, our results illustrate that size-truncating pathogens may 480 suppress cohort resonant effects just as fisheries do (Hidalgo et al. 2011; Botsford et al. 2014).

\section{2-3-year oscillations: Windermere bottom-up forcing}

Superimposed on the top-down 7-8-year and 13-15-year oscillations, the M-SSA also detected a 2-3year oscillation which suggested a direct, bottom-up climate forcing on dissolved phosphorus in the 485 north but not in the south basin. The M-SSA shows that Spring (May-June) temperature was negatively linked to phosphorus concentration during the previous January (Fig. 8). This result might reflect a tendency for warm prings to be preceded by lower wind speeds (resulting in reduced water mixing) and runoff from rainfall, and resultant lower phosphorus concentrations during the previous winter (George and Harris 1985; Thackeray et al. 2012). 
Multiple stressors and food-web apexes

490

The 2-3-year oscillation was also significant in small perch in the south basin. Warm springs were followed by increased numbers of small (age-2) perch in the south basin with a 0.6-y lag (Fig. 8), suggesting a positive effect of temperature on $1+$ and $2+$ perch survival (similar effect as in the 7-8year oscillation). This thermal facilitation presumably operates because higher temperatures (i) increase

495 consumer foraging rates (Vasseur and McCann 2005; Ohlberger et al. 2011a) and food conversion efficiency (Angilletta and Dunham 2003), (ii) increase a competitive asymmetry in favor of small (young) against large (old) fish for the exploitation of resources (Ohlberger et al. 2011a; Edeline et al. 2013); (iii) accelerate fish growth rate and reduce the duration of a small-size-and-high-mortality time span (Vindenes et al. 2014), and (iv) increase fat storage during summer and thus enhance winter

500 survival (Griffiths and Kirkwood 1995; van de Wolfshaar et al. 2008).

Finally, the 2-3-year oscillation was also significant in small pike in the south basin. Warm springs were associated with increased numbers of small pike with almost no lag (0.1-year lag, Fig. 8), i.e., roughly synchronous with the increased abundances of small perch. This synchrony suggests

505 movement-mediated dynamics, in which the increased number of juvenile perch (prey) in the south basin favoured a rapid pike dispersal from the north to the south basin (Haugen et al. 2006; Haugen et al. 2007).

\section{Conclusions}

510 The Windermere case points to general issues for climate and pathogen effects on ecosystems. First, our study highlights reorganization of population age and size structures as a primary mediator of pathogen effects on ecosystem dynamics. In Windermere, total perch biomass remained almost 
Multiple stressors and food-web apexes

constant, indicating that pathogen-induced changes were driven by a biomass-independent reorganization of size structure per se. However, the size-structuring effects of pathogens in food webs

515 remain largely overlooked.

Second, climate warming is often predicted to accelerate consumer metabolism and predation rate, resulting in a magnified top-down control in ecosystems, i.e., in a reinforced control by top consumers over food-web dynamics (Vasseur and McCann 2005; Ohlberger et al. 2011a). This prediction has been

520 empirically validated in both experimental and natural systems (Petchey et al. 1999; Voigt et al. 2003; O’Connor et al. 2009; Rall et al. 2009; Yvon-Durocher et al. 2010; Vucic-Pestic et al. 2011; Shurin et al. 2012; Edeline et al. 2013). Our present results in Windermere further point to increased juvenile survival in top predators as an important driver of warming-induced magnification of top-down control in food webs dominated by ectothermic consumers.

Finally, our results illustrate how relatively simple alterations in the structure of a food-web apex may reverse the effects of a climate-pathogen interaction on ecosystem dynamics. In the linear, tri-trophic food chain of Isle Royale (USA), where wolves feed on moose that feed on trees (Wilmers et al. 2006), an outbreak of canine parvovirus in the wolf population released moose from top-down control, which

530 increased a climate-driven, bottom-up control of moose recruitment through tree productivity. Such a pathogen-induced relaxation of top-down control is to be expected whenever pathogens impact top predators in a food chain. In Windermere, the life-history IGP structure and stage-specific biomass overcompensation in perch instead resulted in a pathogen-induced reinforcement of a climate-driven trophic cascade, i.e., the IGP structure made the top-down effects of climate and pathogen synergistic, 535 not antagonistic as in a food chain. IGP is a very common form of interaction and size or stage 
structuring of populations and interactions is the rule in virtually all biomes. Therefore, our results may potentially apply to many other ecosystems.

540 Acknowledgments. We thank Janice Fletcher, Ben James and other colleagues for undertaking the field and laboratory work of the Windermere fish monitoring programme and Lorenzo Ciannelli for useful discussions. We are also grateful to the Freshwater Biological Association who collected the data at the beginning of the time series. It is a pleasure to thank two anonymous reviewers for their detailed and constructive comments. The Natural Environment Research Council of the UK and the Norwegian

545 Research Council supported part of this work. EE and DC received financial support from the French National Research Agency through projects ANR-10-CEPL-0010 PULSE and ANR-10-BLAN-1709 PHYTBACK. AG was supported by a post-doctoral fellowship of the Groupement d'Interêt Scientifique (GIS) "Réseau de Recherche sur le Développement Soutenable" (R2DS) of the Région Ilede-France. IJW's contribution was part funded by the MARS project (Managing Aquatic ecosystems

550 and water Resources under multiple Stress) under the 7th EU Framework Programme, Theme 6 (Environment including Climate Change), Contract No.: 603378. MG acknowledges support from the US National Science Foundation through grants DMS-1049253 and OCE-1243175.

\section{References}

Abrams PA (2011) Simple life-history omnivory: responses to enrichment and harvesting in systems with intraguild predation. Am Nat 178:305-319. doi: 10.1086/661243

Ajmal M, Hobbs BC (1967) Causes and effects of columnaris-type diseases in fish. Nature 215:142143. doi: $10.1038 / 215142 \mathrm{a} 0$ 
Multiple stressors and food-web apexes

Allen MR, Robertson AW (1996) Distinguishing modulated oscillations from coloured noise in multivariate datasets. Clim Dyn 12:775-784. doi: 10.1007/s003820050142

Allen MR, Smith LA (1996) Monte Carlo SSA: detecting irregular oscillations in the presence of colored noise. J Clim 9:3373-3404. doi: 10.1175/1520-

0442(1996)009<3373:MCSDIO >2.0.CO;2

Altizer S, Dobson A, Hosseini P, et al (2006) Seasonality and the dynamics of infectious diseases. Ecol Lett 9:467-484. doi: 10.1111/j.1461-0248.2005.00879.x

Angilletta MJ, Dunham AE (2003) The temperature-size rule in ectotherms: simple evolutionary explanations may not be general. Am Nat 162:332-342. doi: 10.1086/377187

Bjørnstad ON, Nisbet RM, Fromentin J-M (2004) Trends and cohort resonant effects in age-structured populations. J Anim Ecol 73:1157-1167. doi: 10.1111/j.0021-8790.2004.00888.x

Bodaly RA, Ward RD, Mills CA (1989) A genetic stock study of perch, Perca fluviatilis L., in Windermere. J Fish Biol 34:965-967. doi: 10.1111/j.1095-8649.1989.tb03380.x

Botsford LW, Holland MD, Field JC, Hastings A (2014) Cohort resonance: a significant component of fluctuations in recruitment, egg production, and catch of fished populations. ICES J Mar Sci 71:2158-2170. doi: 10.1093/icesjms/fsu063

Bucke D, Cawley GD, Craig JF, et al (1979) Further studies of an epizootic of perch Perca fluviatilis L., of uncertain aetiology. J Fish Dis 2:297-311. doi: 10.1111/j.1365-2761.1979.tb00172.x

Cazelles B, Cazelles K, Chavez M (2014) Wavelet analysis in ecology and epidemiology: impact of statistical tests. J R Soc Interface 11:20130585. doi: 10.1098/rsif.2013.0585

Cazelles B, Chavez M, Berteaux D, et al (2008) Wavelet analysis of ecological time series. Oecologia 156:287-304. doi: 10.1007/s00442-008-0993-2

Cazelles B, Chavez M, Constantin de Magny G, et al (2007) Time-dependent spectral analysis of epidemiological time-series with wavelets. J R Soc Interface 4:625-636. doi:

$10.1098 /$ rsif.2007.0212

De Roos AM, Schellekens T, Van Kooten T, Persson L (2008) Stage-specific predator species help each other to persist while competing for a single prey. Proc Natl Acad Sci 105:13930-13935.

Edeline E, Ben Ari T, Vøllestad LA, et al (2008) Antagonistic selection from predators and pathogens alters food-web structure. Proc Natl Acad Sci 105:19792-19796.

Edeline E, Lacroix G, Delire C, et al (2013) Ecological emergence of thermal clines in body size. Glob Change Biol 19:3062-3068. doi: 10.1111/gcb.12299

Feliks Y, Ghil M, Robertson AW (2010) Oscillatory climate modes in the eastern Mediterranean and their synchronization with the North Atlantic Oscillation. J Clim 23:4060-4079. doi: 


\subsection{5/2010JCLI3181.1}

Feliks Y, Ghil M, Simonnet E (2004) Low-frequency variability in the midlatitude atmosphere induced by an oceanic thermal front. J Atmospheric Sci 61:961-981. doi: 10.1175/15200469(2004)061<0961:LVITMA>2.0.CO;2

Feliks Y, Groth A, Robertson AW, Ghil M (2013) Oscillatory climate modes in the Indian monsoon, North Atlantic, and tropical Pacific. J Clim 26:9528-9544. doi: 10.1175/JCLI-D-13-00105.1

George DG, Harris GP (1985) The effect of climate on long-term changes in the crustacean zooplankton biomass of Lake Windermere, UK. Nature 316:536-539. doi: 10.1038/316536a0

Ghil M, Allen MR, Dettinger MD, et al (2002) Advanced spectral methods for climatic time series. Rev Geophys 40:1-41. doi: 10.1029/2000RG000092

Ghil M, Vautard R (1991) Interdecadal oscillations and the warming trend in global temperature time series. Nature 350:324-327.

Griffiths D, Kirkwood RC (1995) Seasonal variation in growth, mortality and fat stores of roach and perch in Lough Neagh, northern Ireland. J Fish Biol 47:537-554. doi: 10.1111/j.10958649.1995.tb01920.x

Groth A, Ghil M (2011) Multivariate singular spectrum analysis and the road to phase synchronization. Phys Rev E 84:036206.

Groth A, Ghil M (2015) Monte Carlo Singular Spectrum Analysis (SSA) revisited: detecting oscillator clusters in multivariate datasets. J Clim 28:7873-7893. doi: 10.1175/JCLI-D-15-0100.1

Gurney WSC, Nisbet RM (1985) Fluctuation periodicity, generation separation, and the expression of larval competition. Theor Popul Biol 28:150-180. doi: 10.1016/0040-5809(85)90026-7

Harvell CD (2002) Climate warming and disease risks for terrestrial and marine biota. Science 296:2158-2162. doi: 10.1126/science.1063699

Hatcher MJ, Dick JTA, Dunn AM (2006) How parasites affect interactions between competitors and predators. Ecol Lett 9:1253-1271. doi: 10.1111/j.1461-0248.2006.00964.x

Haugen TO, Winfield IJ, Vøllestad LA, et al (2007) Density dependence and density independence in the demography and dispersal of pike over four decades. Ecol Monogr 77:483-502.

Haugen TO, Winfield IJ, Vøllestad LA, et al (2006) The ideal free pike: 50 years of fitness-maximizing dispersal in Windermere. Proc R Soc B Biol Sci 273:2917-2924. doi: 10.1098/rspb.2006.3659

Hidalgo M, Rouyer T, Molinero JC, et al (2011) Synergistic effects of fishing-induced demographic changes and climate variation on fish population dynamics. Mar Ecol Prog Ser 426:1-12. doi: $10.3354 /$ meps09077 
Multiple stressors and food-web apexes

Holdo RM, Sinclair ARE, Dobson AP, et al (2009) A disease-mediated trophic cascade in the Serengeti and its implications for ecosystem C. PLoS Biol 7:e1000210. doi:

10.1371/journal.pbio. 1000210

Holt RD, Polis GA (1997) A theoretical framework for intraguild predation. Am Nat 149:745-764. doi: $10.2307 / 2463547$

Hudson PJ, Dobson AP, Lafferty KD (2006) Is a healthy ecosystem one that is rich in parasites? Trends Ecol Evol 21:381-385. doi: 10.1016/j.tree.2006.04.007

IPCC (2014) Climate change 2014: synthesis report. Contribution of Working Groups I, II and III to the fifth assessment report of the Intergovernmental Panel on Climate Change. Intergovernmental Panel on Climate Change, Geneva, Switzerland

Langangen Ø, Edeline E, Ohlberger J, et al (2011) Six decades of pike and perch population dynamics in Windermere. Fish Res 109:131-139. doi: 10.1016/j.fishres.2011.01.029

Möllmann C, Diekmann R (2012) Marine ecosystem regime shifts induced by climate and overfishing: a review for the northern hemisphere. Adv Ecol Res 47:303-347. doi: 10.1016/B978-0-12398315-2.00004-1

O'Connor MI, Piehler MF, Leech DM, et al (2009) Warming and resource availability shift food web structure and metabolism. PLoS Biol 7:e1000178. doi: 10.1371/journal.pbio.1000178

Ohlberger J, Edeline E, Vøllestad LA, et al (2011a) Temperature-driven regime shifts in the dynamics of size-structured populations. Am Nat 177:211-223. doi: 10.1086/657925

Ohlberger J, Langangen Ø, Edeline E, et al (2011b) Stage-specific biomass overcompensation by juveniles in response to increased adult mortality in a wild fish population. Ecology 92:21752182 .

Ohlberger J, Langangen Ø, Edeline E, et al (2011c) Pathogen-induced rapid evolution in a vertebrate life-history trait. Proc R Soc B Biol Sci 278:35-41. doi: 10.1098/rspb.2010.0960

Ohlberger J, Langangen Ø, Edeline E, et al (2011d) Stage-specific biomass overcompensation by juveniles in response to increased adult mortality in a wild fish population. Ecology 92:21752182.

Oksanen L, Fretwell SD, Arruda J, Niemela P (1981) Exploitation ecosystems in gradients of primary productivity. Am Nat 118:240-261. doi: 10.2307/2460513

Paxton CGM, Winfield IJ, Fletcher JM, et al (2004) Biotic and abiotic influences on the recruitment of male perch in Windermere, U.K. J Fish Biol 65:1622-1642. doi: 10.1111/j.00221112.2004.00573.x

Paxton CGM, Winfield IJ, Fletcher JM, et al (2009) Investigation of first year biotic and abiotic 
influences on the recruitment of pike Esox lucius over 48 years in Windermere, UK. J Fish Biol 74:2279-2298. doi: 10.1111/j.1095-8649.2009.02235.x

Petchey OL, McPhearson PT, Casey TM, Morin PJ (1999) Environmental warming alters food-web structure and ecosystem function. Nature 402:69-72. doi: 10.1038/47023

Plaut G, Ghil M, Vautard R (1995) Interannual and interdecadal variability in 335 years of central England temperatures. Science 268:710-713. doi: 10.1126/science.268.5211.710

Plaut G, Vautard R (1994) Spells of low-frequency oscillations and weather regimes in the northern hemisphere. J Atmospheric Sci 51:210-236. doi: 10.1175/15200469(1994)051<0210:SOLFOA $>2.0 . \mathrm{CO} ; 2$

Pokorná L, Huth R (2015) Climate impacts of the NAO are sensitive to how the NAO is defined. Theor Appl Climatol 119:639-652. doi: 10.1007/s00704-014-1116-0

Rall BC, Vucic-Pestic O, Ehnes RB, et al (2009) Temperature, predator-prey interaction strength and population stability. Glob Change Biol 16:2145-2157. doi: 10.1111/j.1365-2486.2009.02124.x

Rouyer T, Fromentin JM, Stenseth NC, Cazelles B (2008) Analysing multiple time series and extending significance testing in wavelet analysis. Mar Ecol Prog Ser 359:11-23. doi: 10.3354/meps07330

Shurin JB, Clasen JL, Greig HS, et al (2012) Warming shifts top-down and bottom-up control of pond food web structure and function. Philos Trans R Soc B Biol Sci 367:3008-3017. doi: $10.1098 /$ rstb.2012.0243

Thackeray SJ, Henrys PA, Jones ID, Feuchtmayr H (2012) Eight decades of phenological change for a freshwater cladoceran: what are the consequences of our definition of seasonal timing? Freshw Biol 57:345-359. doi: 10.1111/j.1365-2427.2011.02614.x

van de Wolfshaar KE, de Roos AM, Persson L (2008) Population feedback after successful invasion leads to ecological suicide in seasonal environments. Ecology 89:259-268. doi: 10.1890/062058.1

Vasseur DA, McCann KS (2005) A mechanistic approach for modeling temperature-dependent consumer-resource dynamics. Am Nat 166:184-198.

Vautard R, Ghil M (1989) Singular spectrum analysis in nonlinear dynamics, with applications to paleoclimatic time series. Phys Nonlinear Phenom 35:395-424.

Vindenes Y, Edeline E, Ohlberger J, et al (2014) Effects of climate change on trait-based dynamics of a top predator in freshwater ecosystems. Am Nat 183:243-256. doi: 10.1086/674610

Voigt W, Perner J, Davis AJ, et al (2003) Trophic levels are differentially sensitive to climate. Ecology 84:2444-2453. doi: 10.1890/02-0266

Vucic-Pestic O, Ehnes RB, Rall BC, Brose U (2011) Warming up the system: higher predator feeding 
rates but lower energetic efficiencies. Glob Change Biol 17:1301-1310. doi: 10.1111/j.13652486.2010.02329.x

Wilmers CC, Post E, Peterson RO, Vucetich JA (2006) Predator disease out-break modulates top-down, bottom-up and climatic effects on herbivore population dynamics. Ecol Lett 9:383-389. doi: 10.1111/j.1461-0248.2006.00890.x

Winfield IJ, Fletcher JM, Ben James J (2012) Long-term changes in the diet of pike (Esox lucius), the top aquatic predator in a changing Windermere. Freshw Biol 57:373-383. doi: 10.1111/j.13652427.2011.02607.x

Yvon-Durocher G, Jones JI, Trimmer M, et al (2010) Warming alters the metabolic balance of ecosystems. Philos Trans R Soc B Biol Sci 365:2117-2126. doi: 10.1098/rstb.2010.0038 
Multiple stressors and food-web apexes

\section{Electronic Supplemental Material}

One single file containing:

- supplemental materials and methods with references.

$560 \quad-$ supplemental figures S1 to S3.

- supplemental figure legends.

\section{Figure Captions}

Fig. 1. Time series (1946 to 2002) for the north (N) and south (S) basins of Windermere showing the raw data (blue), the fitted trend (green) and the reconstructed components (RCs) for the 7-8-year oscillation ( $\mathrm{n}=58$ years per time series). Trends were estimated directly in the M-SSA as RCs 1-2.

570 Vertical dotted lines show peaks in summer temperature, the leading oscillation, and $\tau$ indicates the corresponding delay (lag) of each time series. Bold titles indicate time series for which the 7-8-year oscillation was statistically significant $(\mathrm{p}<0.05)$. The $\%$ indicates fraction of total variance explained by the 7-8 year oscillation. Temp Spring degree $=$ sum of degree days above $14^{\circ} \mathrm{C}$ in May and June, Temp Summer Degree $=$ sum of degree days above $14^{\circ} \mathrm{C}$ in August and September. Fish abundances

575 are in number of fish caught per 30-yd net day (pike) or per trap used 6 weeks on the spawning ground (perch). Phosphorus concentration is given as the average $\mathrm{mg} \cdot \mathrm{l}^{-1}$ total reactive $\mathrm{P}$ during January

Fig. 2. Interaction graphic for the Windermere time series handled in this study. Phos $=$ phosphorus, other variables are as in Fig. 1. The compartments for which we have quantitative data are darkened,

580 while the perch pathogen is only known to be present or absent. Thin lines indicate an interaction; bold, single-headed arrows indicate thermal forcing; bold, double-headed arrow indicates pike dispersal between the two basins of the lake 
Fig. 3. Wavelet power spectrum (WPS) of normalized and detrended fish time series in the north (N)

585 and south $(\mathrm{S})$ basins of Windermere $(\mathrm{n}=58$ years/time series, except Phosphorus for which data is lacking in 1956, 1958 and 1997). Fish variables are as described in Fig. 1. Colour code: increasing spectrum intensity from white to dark red; black dashed lines show statistically significant area (threshold of $95 \% \mathrm{CI}$ ); the fine black curve delimits the cone of influence (region not influenced by edge effects). Edge effects resulting from the trade-off between spectral and temporal resolution (see 590 the methods) may be considered unimportant if a significant region of the spectrum also extends inside the cone of influence. Boxes on the right hand side of each WPS show the global wavelet power spectrum (GWPS, solid blue line) with its threshold value of 95\% CI (dashed black line) (Cazelles et al. 2014)

595 Fig. 4. Wavelet power spectrum (WPS) of normalized and detrended time series for abiotic covariates in Windermere. Abiotic variables are as described in Fig. 1. Colour and line codes as in Fig. 3

Fig. 5. Coherence analysis of normalized and detrended fish time series in the north (N) and south (N) basins of Windermere. Colour code: increasing coherence intensity from white to dark red; white 600 dashed lines show statistically significant area as computed by bootstrapping (threshold of $95 \% \mathrm{CI}$ ); the fine black curve delimits the cone of influence (region not influenced by edge effects)

Fig. 6. Phase analysis of reconstructed fish oscillations in the 7-8-year frequency range from the coherence analysis in Fig. 5. Red solid lines $=$ small perch, Blue solid lines $=$ small pike, Red dashed 605 lines $=$ large perch, Blue dashed lines $=$ large pike 
Multiple stressors and food-web apexes

Fig. 7. Windermere time series for which the M-SSA detected a statistically significant $(p<0.05) 13$ 15 year oscillation. Color code, lines and symbols are as in Fig. 1

610 Fig. 8. Windermere time series for which the M-SSA detected a statistically significant $(\mathrm{p}<0.05) 2-3$ year oscillation. Color code, lines and symbols are as in Fig. 1 

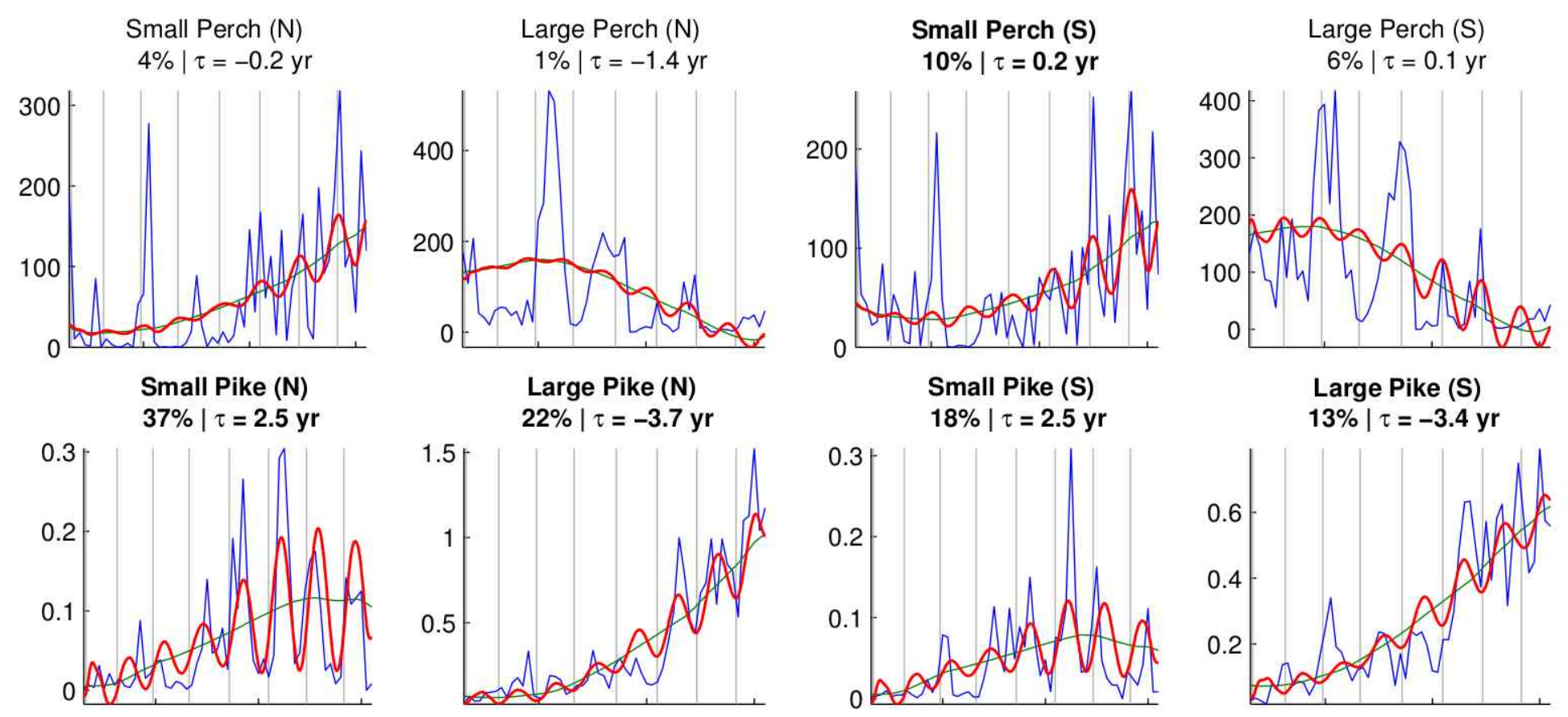

Phosphorus (N)

$3 \% \mid \tau=0.7 \mathrm{yr}$

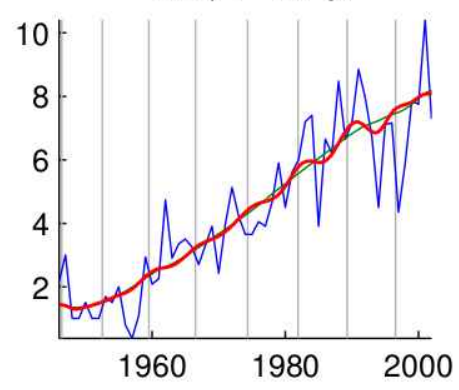

Phosphorus (S)

$15 \% \mid \tau=1.6 \mathrm{yr}$

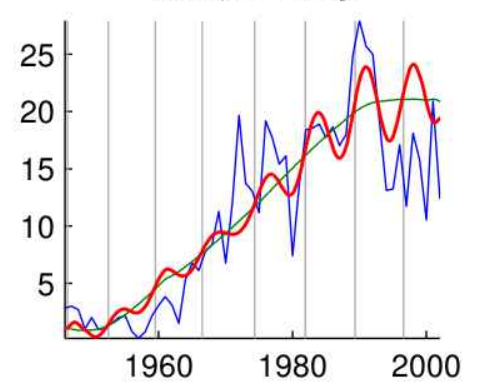

Temp Spring degree $2 \% \mid \tau=0.6 \mathrm{yr}$

Temp Summer degree $21 \% \mid \tau=0.0 \mathrm{yr}$
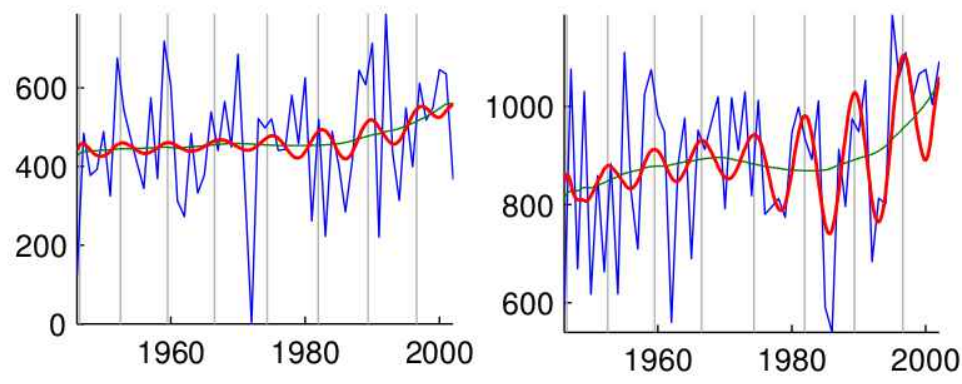

Raw time series

Trend component

7.4-yr oscillation

Fig. 1. 
Multiple stressors and food-web apexes

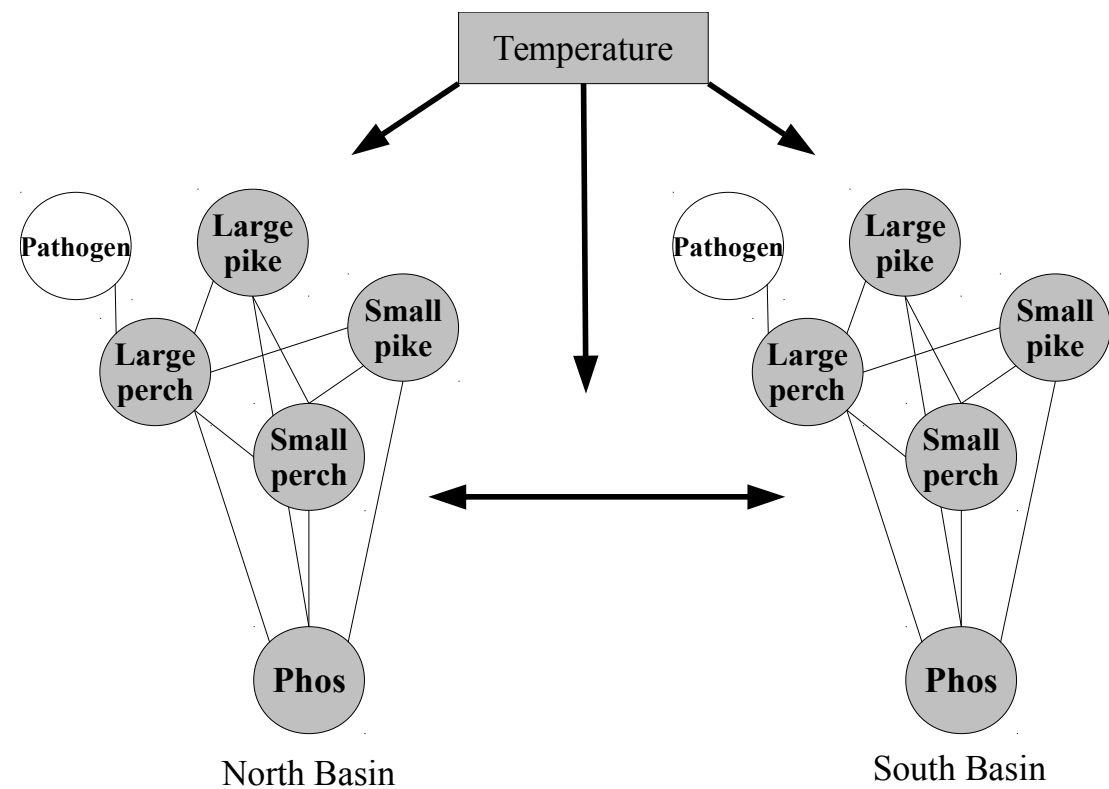

Fig. 2. 
A. Small perch $(\mathrm{N})$

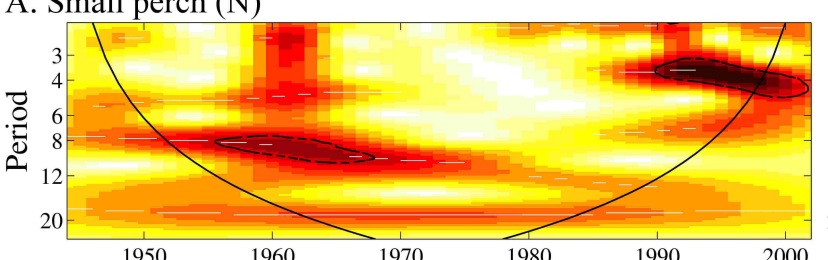

B. Large perch $(\mathrm{N})$
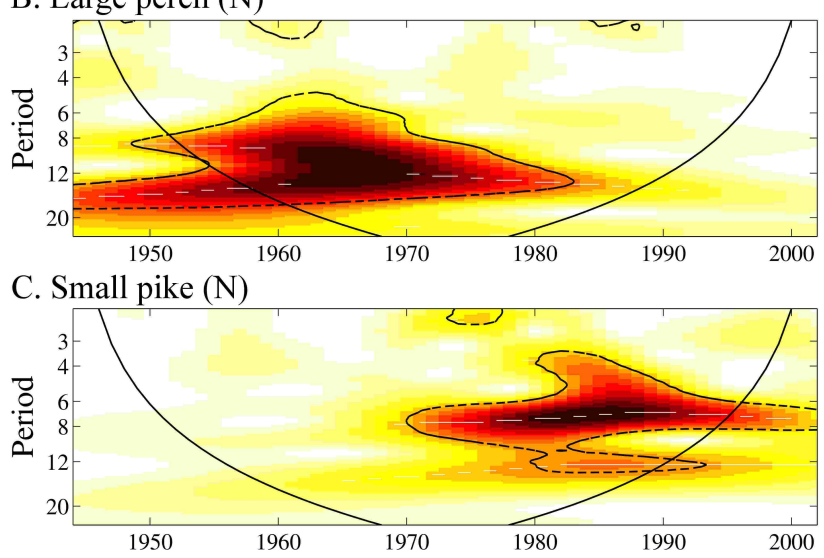

D. Large pike $(\mathrm{N})$
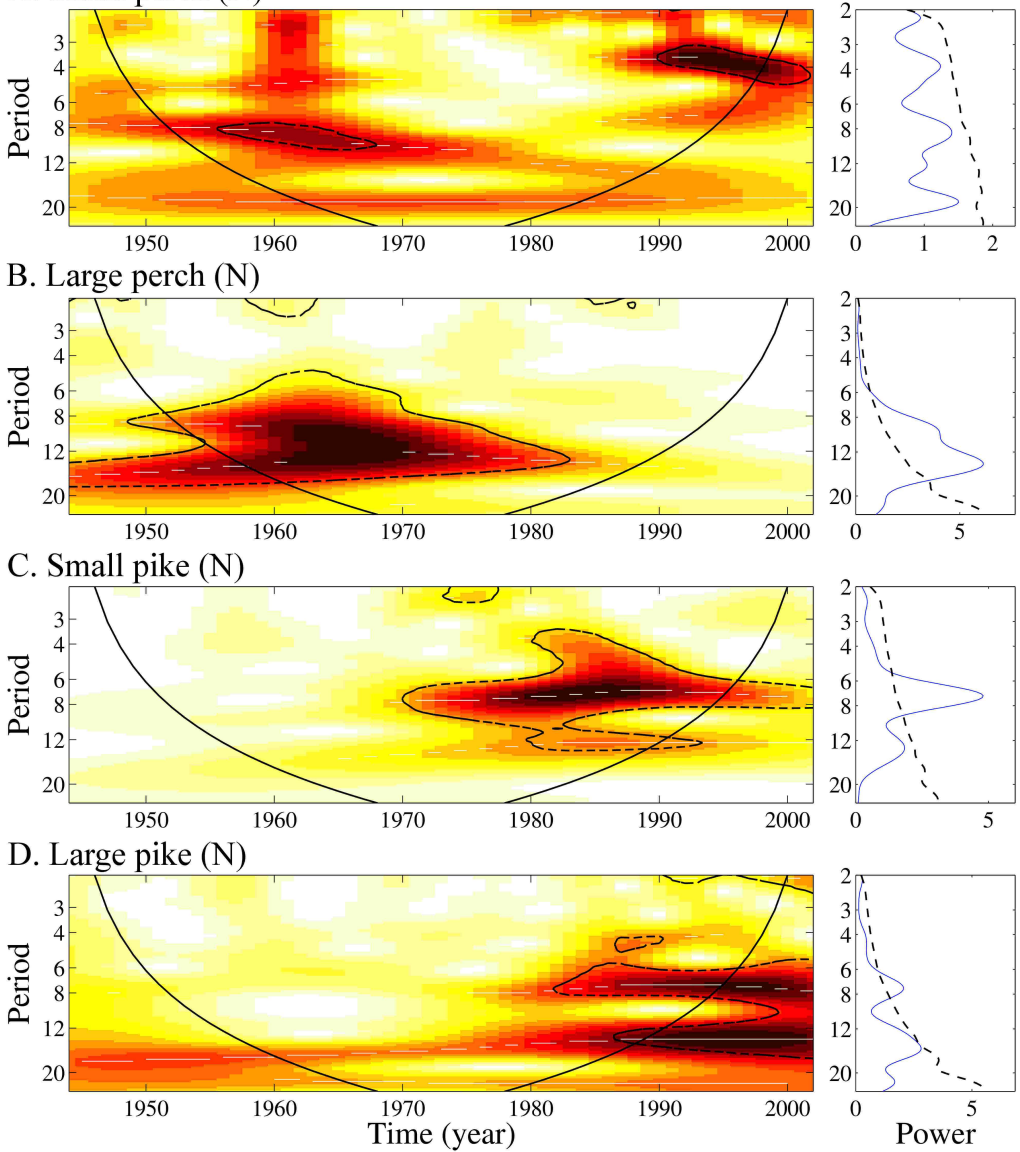

E. Small perch (S)

\section{H. Large pike (S)}
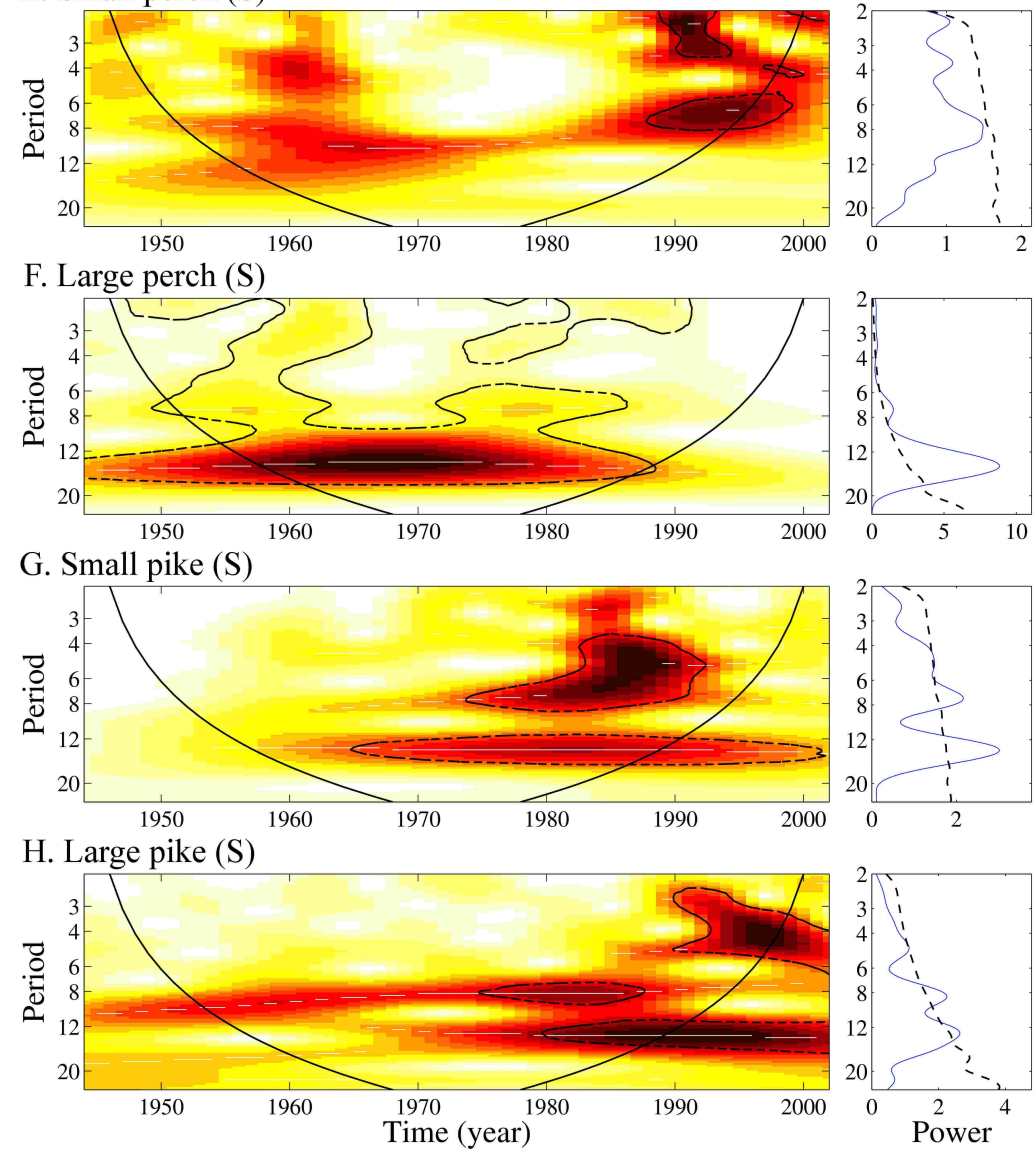

F. Large perch (S)
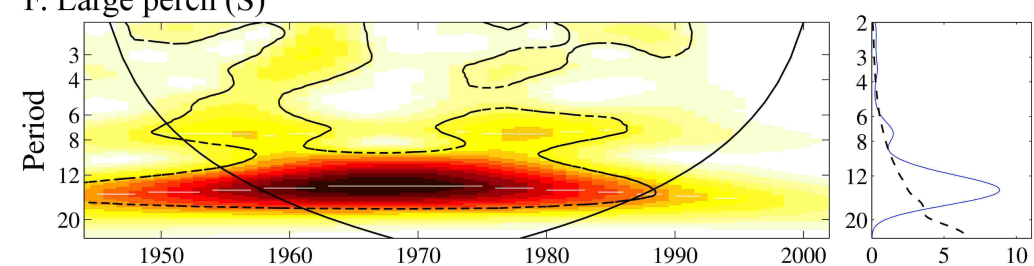

G. Small pike (S)
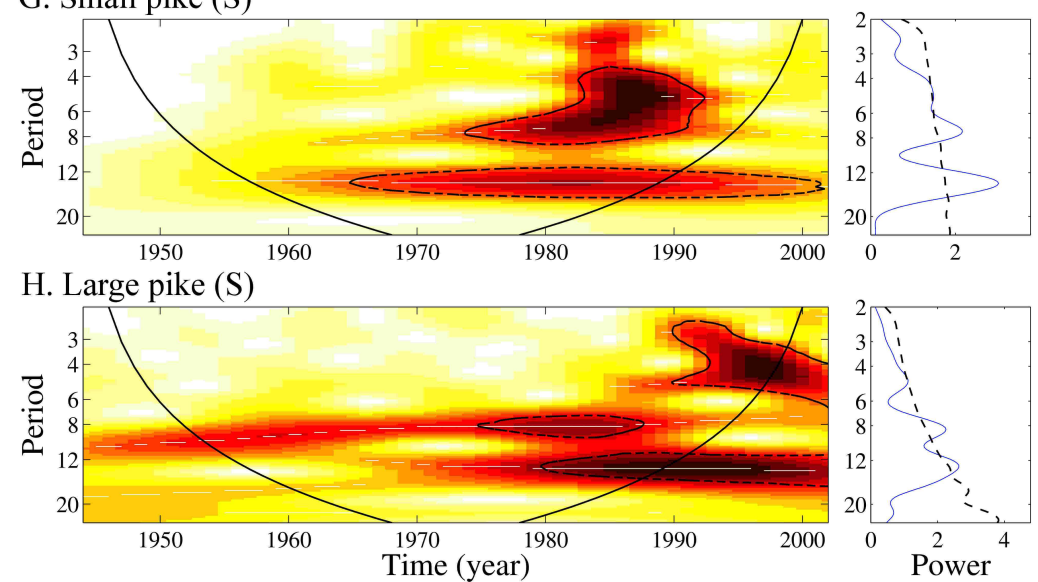

Fig. 3. 
Multiple stressors and food-web apexes
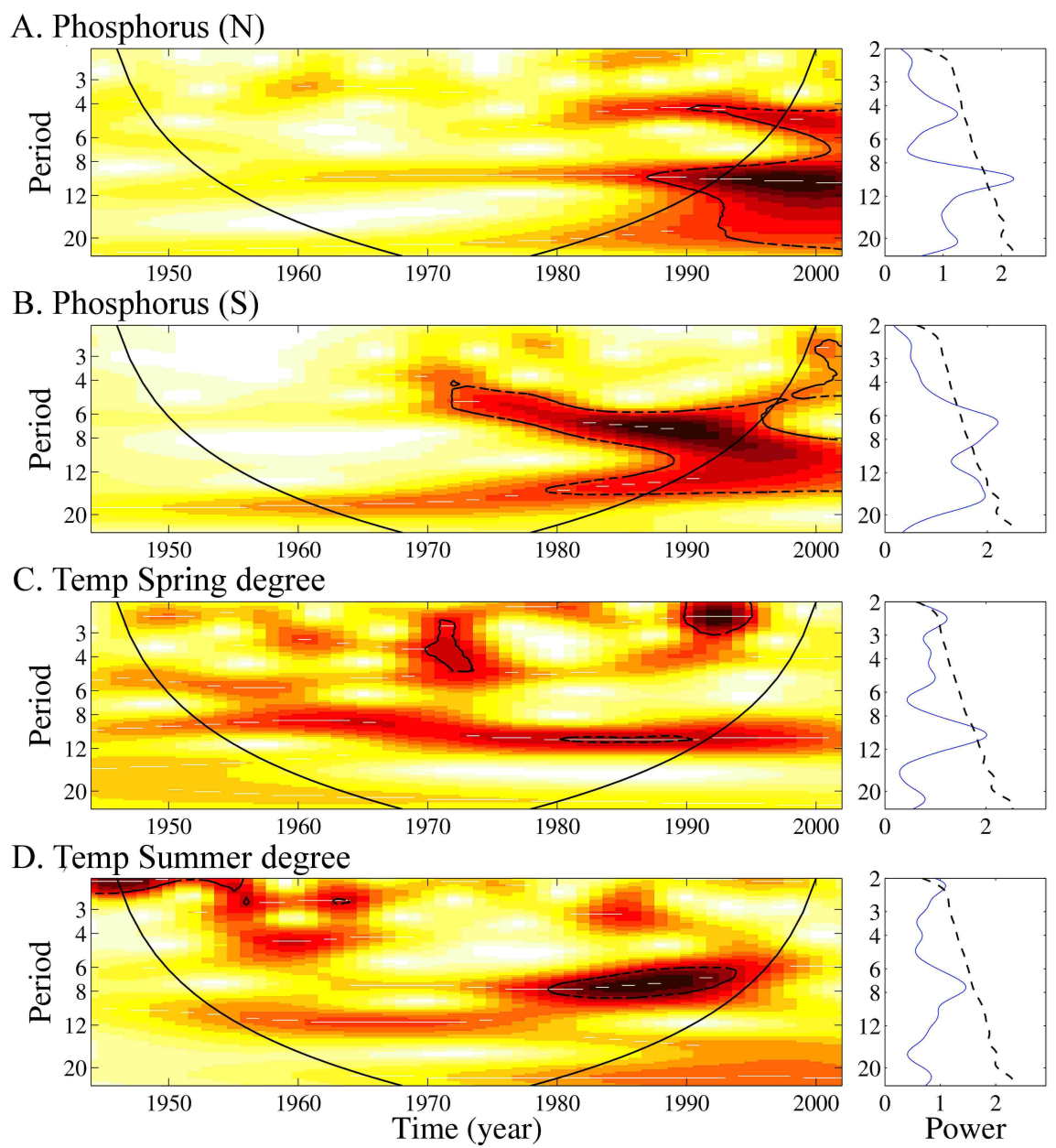

\section{$620 \quad$ Fig. 4.}


A. Small perch vs. small pike (N)

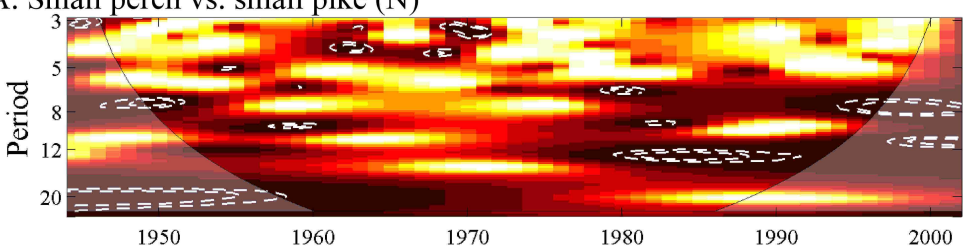

B. Small perch vs. large pike $(\mathrm{N})$

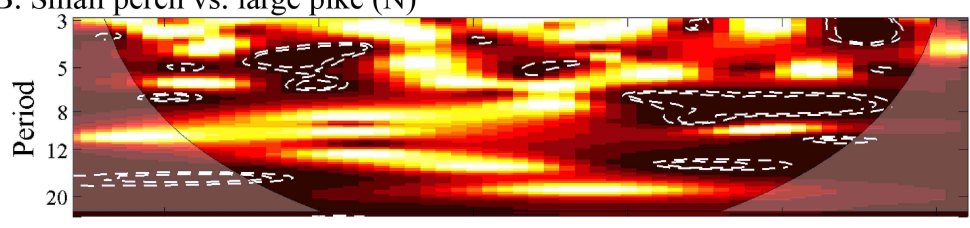

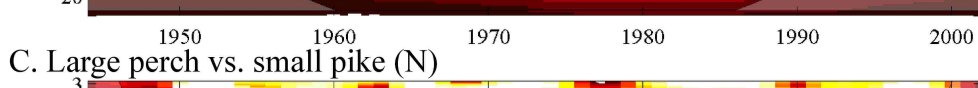

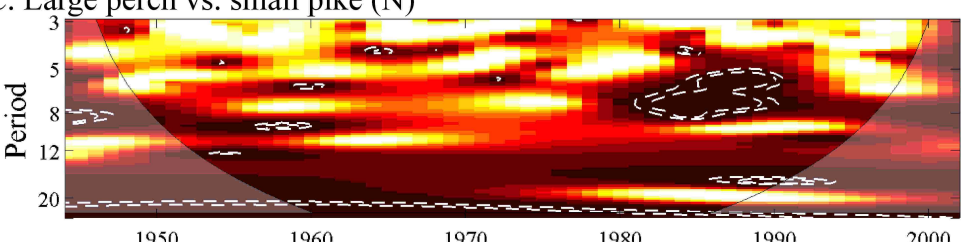

D. Large perch vs. large pike $(\mathrm{N})$ $970 \quad 198$ 1990

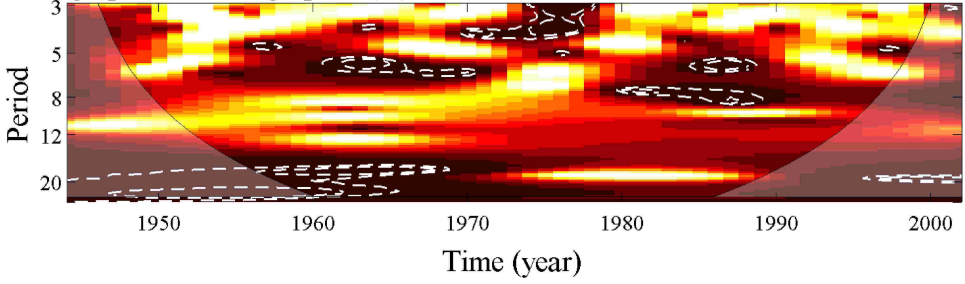

E. Small perch vs. small pike (S)

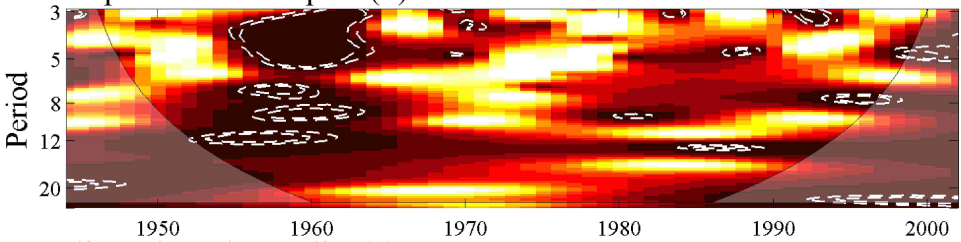

F. Small perch vs. large pike (S)

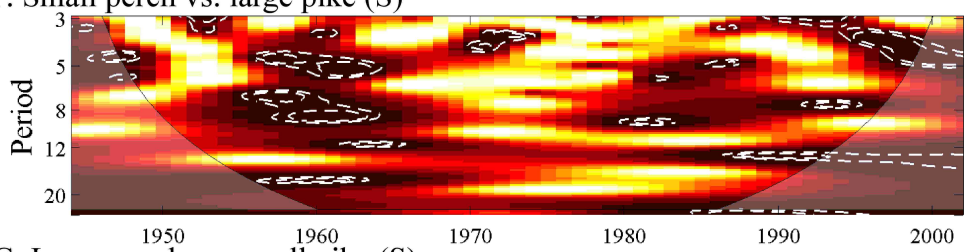

G. Large perch vs. small pike (S)

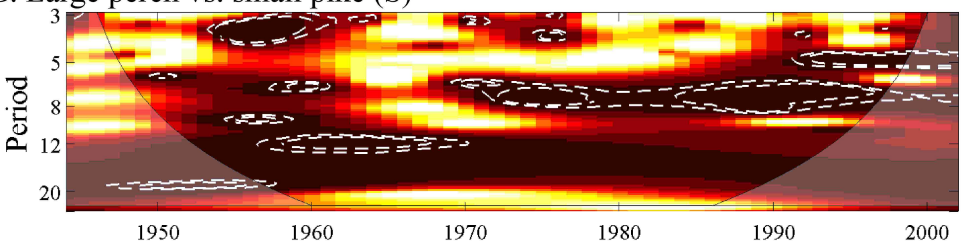

H. Large perch vs. large pike (S)

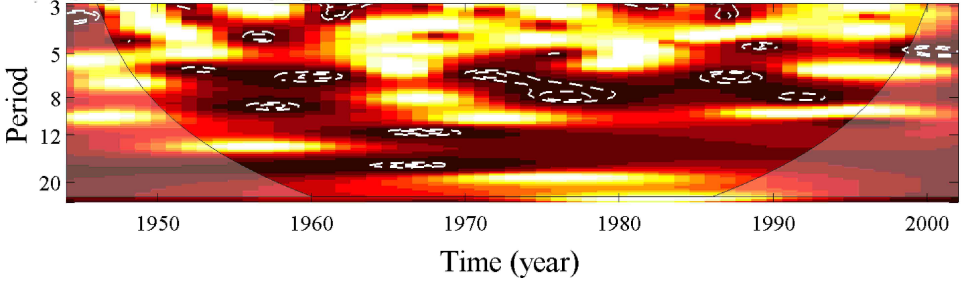

Fig. 5. 
Multiple stressors and food-web apexes

\section{A. North basin}

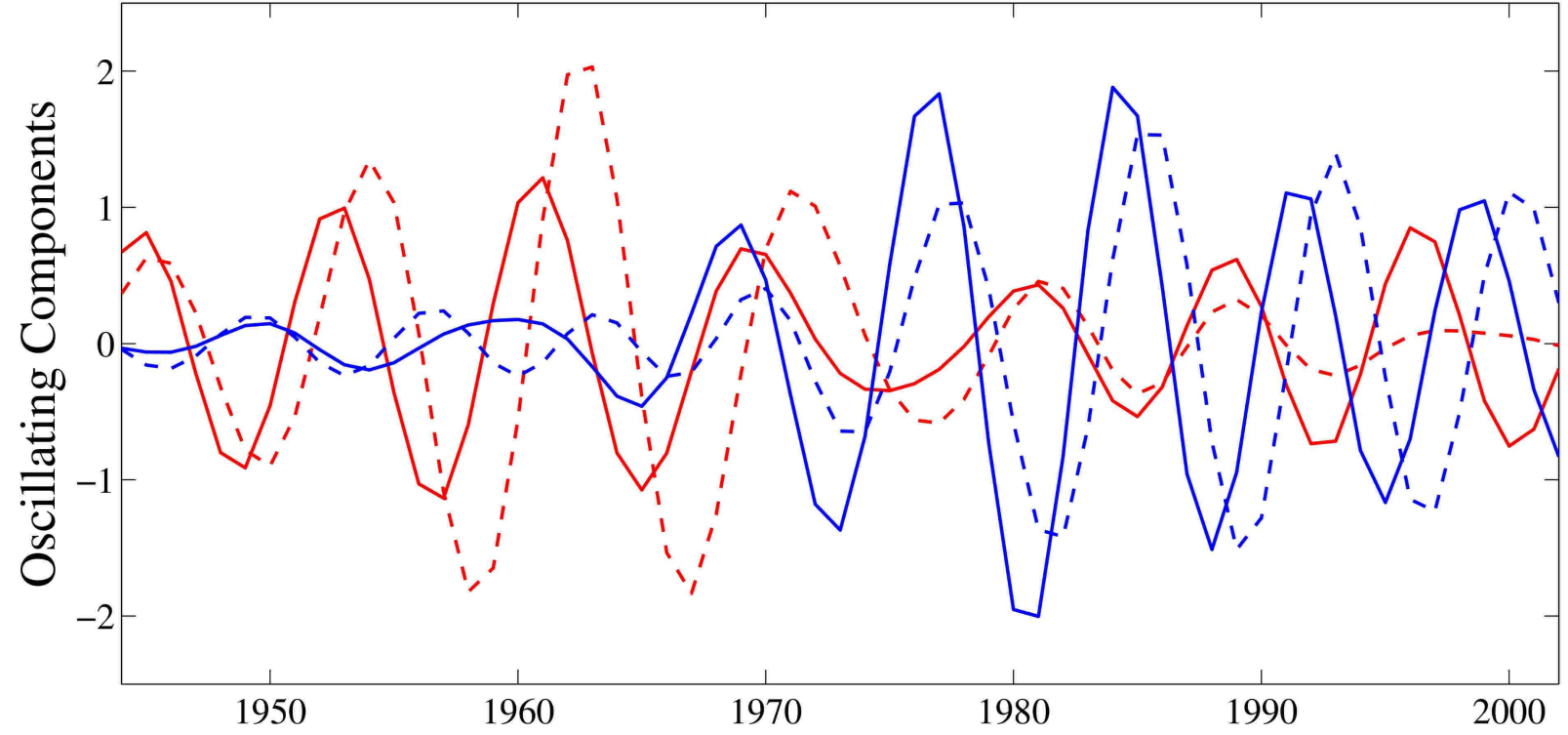

\section{B. South basin}

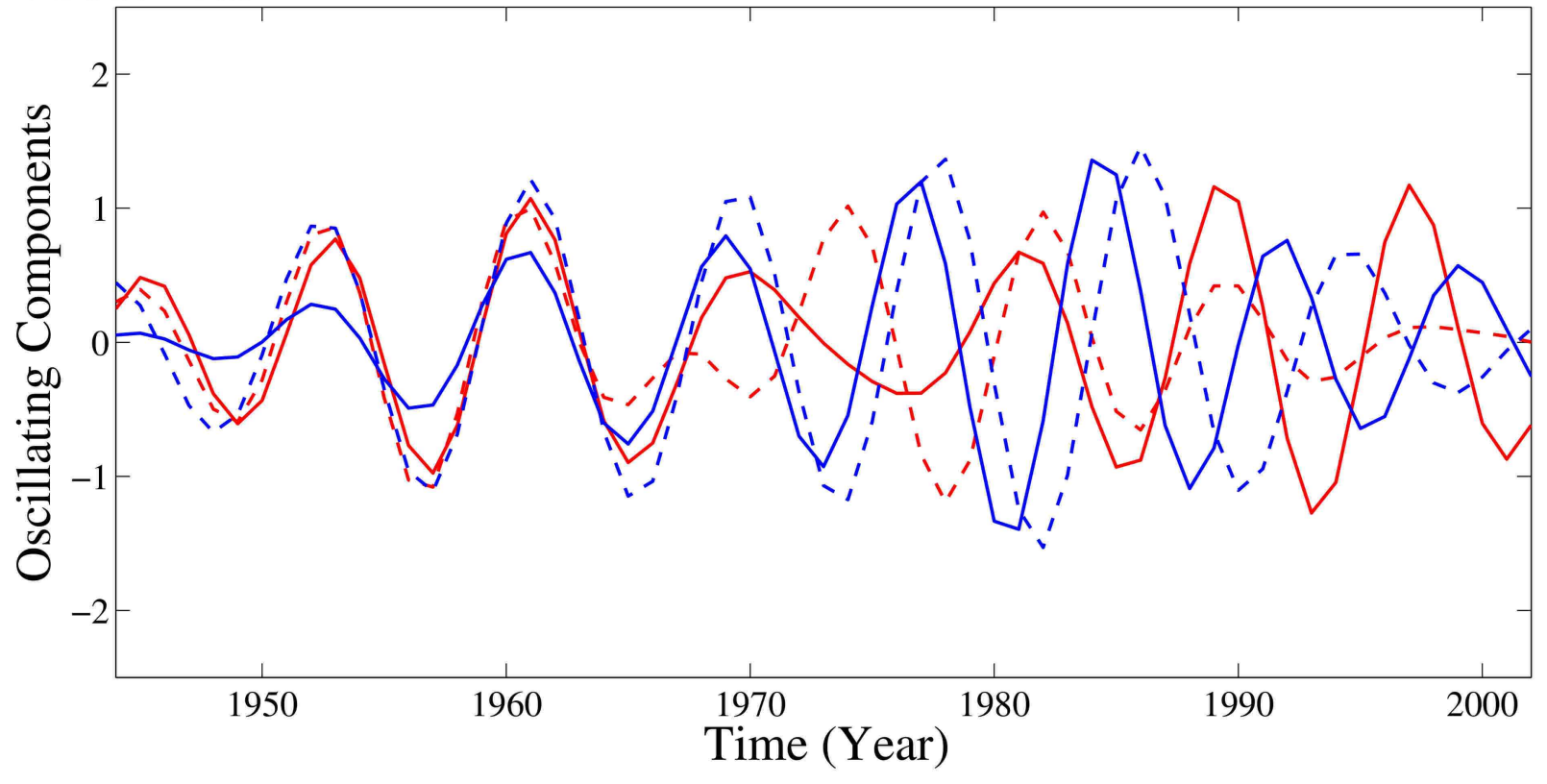

Fig. 6. 

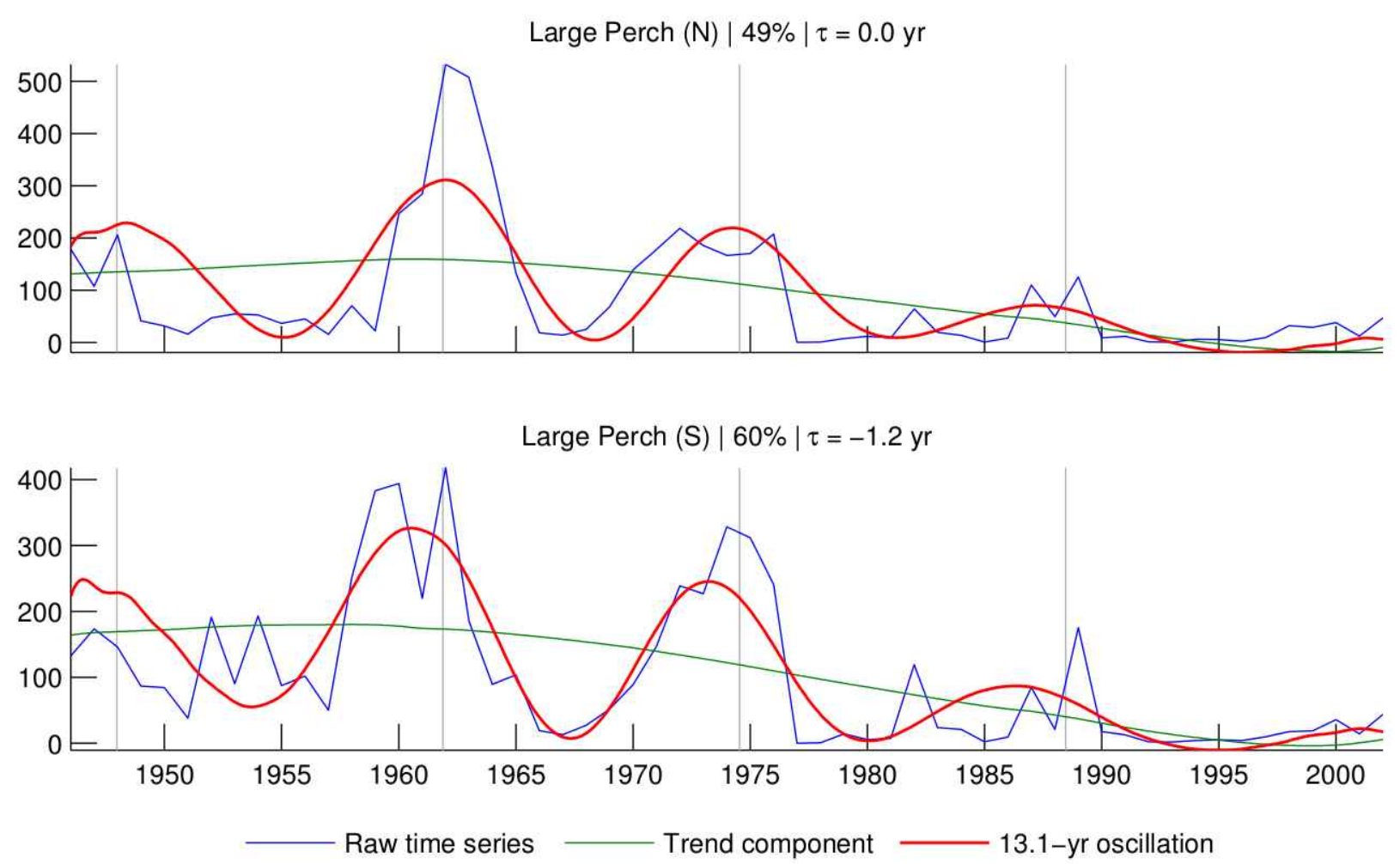

Fig. 7. 
Multiple stressors and food-web apexes

Temp Spring degree $|20 \%| \tau=0.0 \mathrm{yr}$

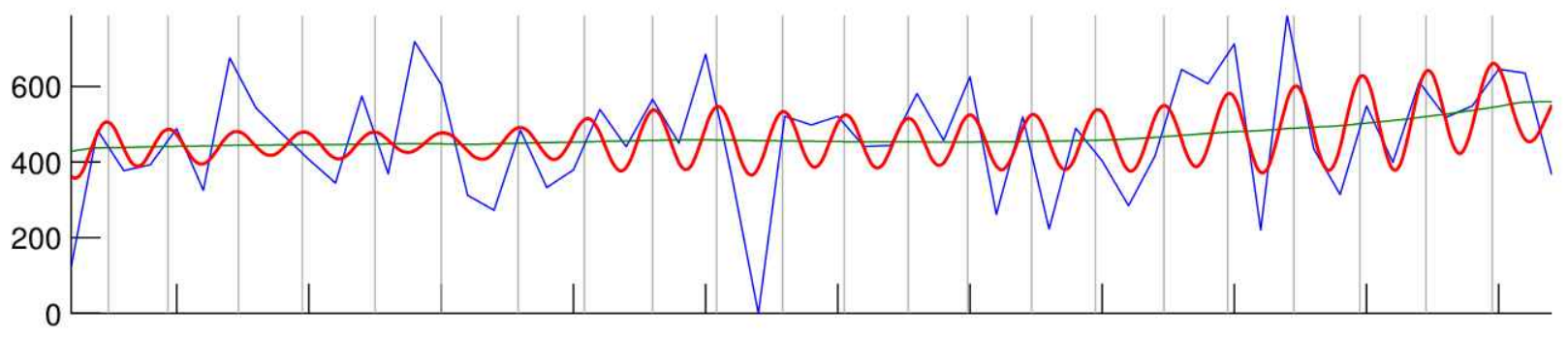

Small Pike (S) $|7 \%| \tau=0.1 \mathrm{yr}$

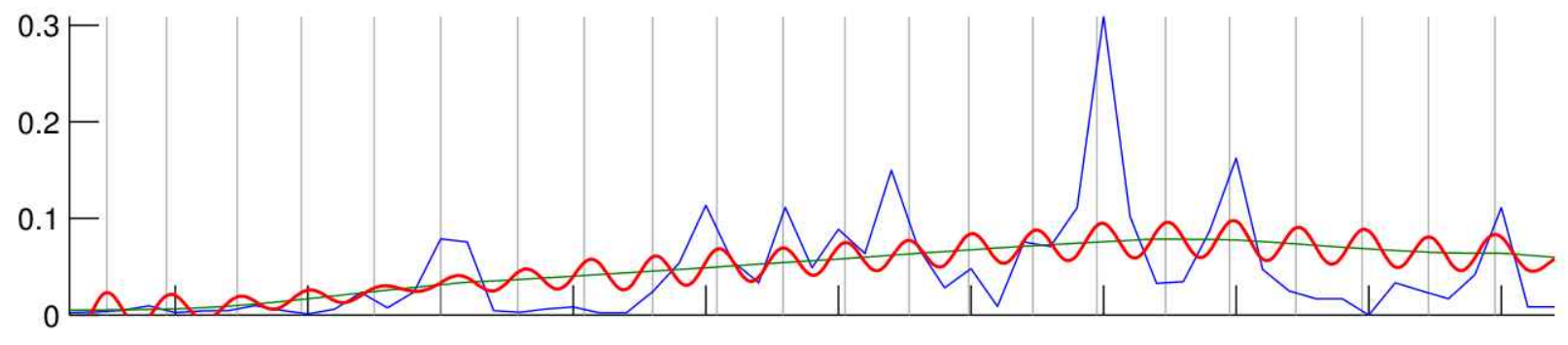

Small Perch (S) $|6 \%| \tau=0.6 \mathrm{yr}$

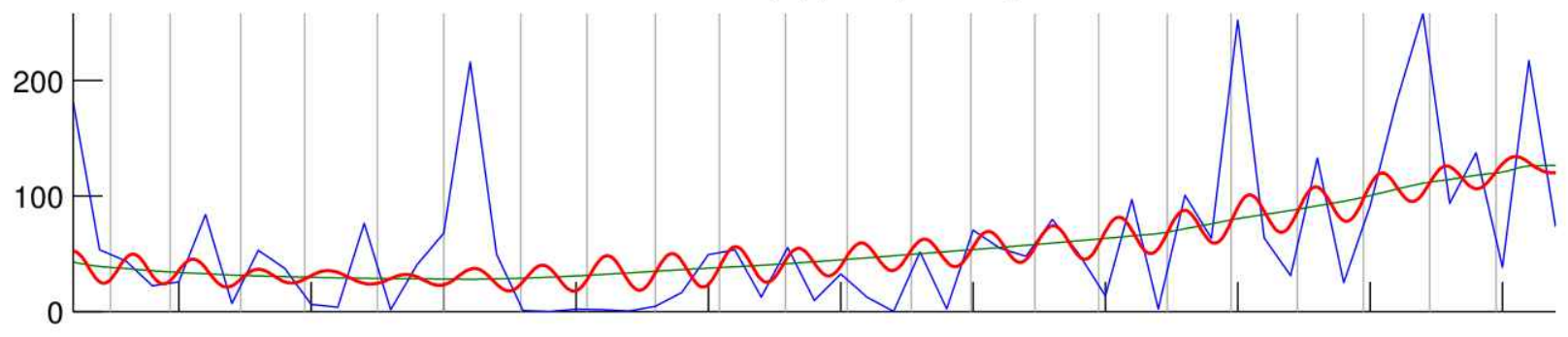

Phosphorus (N) $|8 \%| \tau=1.2 \mathrm{yr}$

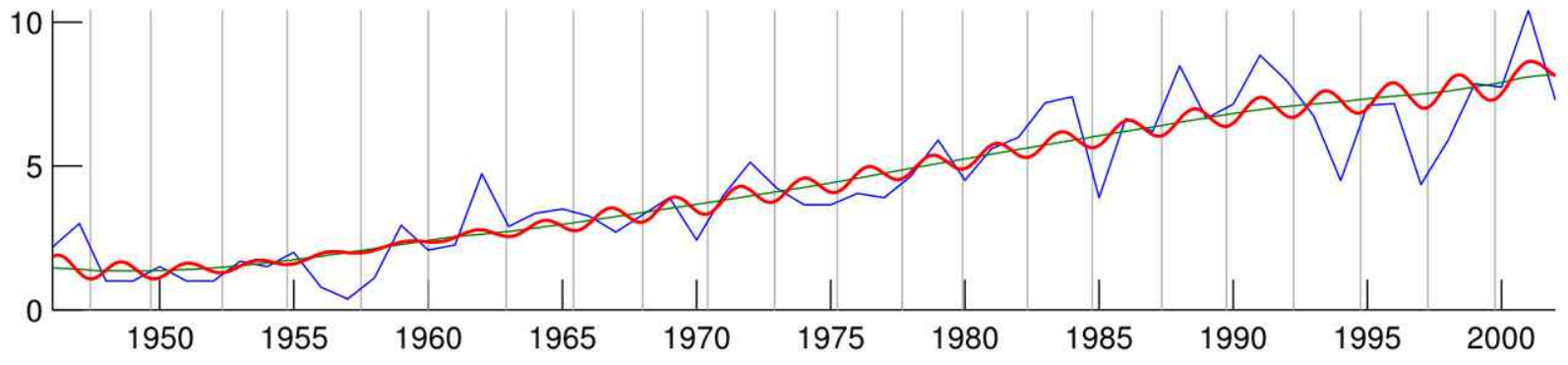

Fig. 8. 